\title{
SKILL-BIASED TECHNOLOGICAL CHANGE, UNEMPLOYMENT, AND BRAIN DRAIN
}

\author{
Harald Fadinger \\ University of Vienna
}

\author{
Karin Mayr \\ University of Vienna
}

\begin{abstract}
We develop a model of directed technology adoption, frictional unemployment, and migration to examine the effects of a change in skill endowments on the wages, employment rates, and emigration rates of skilled and unskilled workers. We find that, depending on the elasticity of substitution between skilled and unskilled workers and the elasticity of the matching function, an increase in the skill ratio can reduce both the relative unemployment rate and the relative emigration rate (brain drain) of skilled workers. We provide numerical simulations to support our findings and show that the effects are empirically relevant and potentially sizable. (JEL: F22, J61, J64, O33)
\end{abstract}

\section{Introduction}

Models of skill-biased technological change have become increasingly popular in explaining the rise in the relative wage of skilled workers (skill premium) that has been observed around the world in the last decade or so (e.g., Acemoglu 2003; Thoenig and Verdier 2003; Epifani and Gancia 2008). Such models have also been used to explain cross-country differences in income per worker (e.g., Acemoglu and Zilibotti 2001; Caselli and Coleman 2006; Gancia, Müller, and Zilibotti 2011). A major challenge when testing these models in a cross-country context is that their main empirical prediction concerns a link between the skill premium and the relative abundance of skilled workers. However, the comparable cross-country data on skill premia-which would be required to test this hypothesis - are scarce and of questionable quality. So in this paper we develop two useful extensions of Acemoglu's $(1998,2002)$

The editor in charge of this paper was Fabrizio Zilibotti.

Acknowledgments: We thank the editor, Fabrizio Zilibotti, and three anonymous referees for suggestions that significantly improved the paper. For helpful comments we also thank Alejandro Cuñat and Monika Merz as well as participants in seminars at the Vienna Graduate School of Economics, the Vienna Institute for International Economic Studies, the 2011 meeting of the European Economic Association, the 2012 meeting of the Royal Economic Society, the 3rd NORFACE Migration Conference, the 5th FIW Conference in International Economics, and the 5th World Bank Conference on Migration and Development. Karin Mayr gratefully acknowledges financial support from the NORFACE research program on Migration in Europe-Social, Economic, Cultural, and Policy Dynamics.

E-mail: harald.fadinger@univie.ac.at (Fadinger); karin.mayr@univie.ac.at (Mayr) 


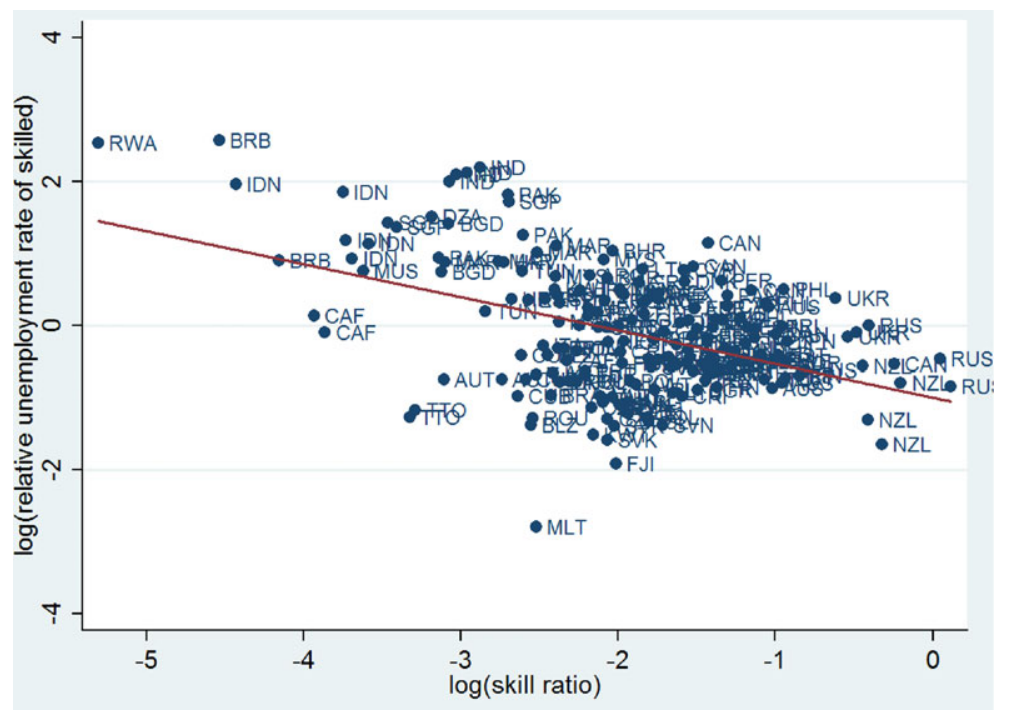

FIGURE 1. Skill ratio and relative unemployment. The figure shows the simple correlation between the $\log$ relative unemployment rate of skilled workers and the log skill ratio. The regression coefficient of $\log$ skill ratio is -0.46 (robust SE: 0.10 ), with $R$-squared of 0.20 . Data are for an unbalanced panel of 75 countries in 5-year intervals from 1980-2005.

model of directed technological change. We augment the standard model for two components: skill-specific frictional unemployment and skill-specific migration. With these extensions, the model yields clear predictions about how skill ratios are related to both the unemployment and the emigration rates of skilled workers, where the latter is referred to as "brain drain". For these factors, comparable cross-country data are readily available.

To illustrate the idea, Figure 1 plots the relative unemployment rate of skilled and unskilled workers for panels of OECD and non-OECD countries against relative skill endowments. ${ }^{1}$ It is apparent that countries with a higher skill ratio have a substantially lower unemployment rate of skilled versus unskilled workers. Figure 2 plots log changes in relative unemployment rates against log changes in skill ratio. Again we see a strong negative correlation - contrary to results derived from models in which the relative demand for skill is downward sloping, since in this case a higher relative abundance of skill should result in higher relative unemployment rates of skilled workers. ${ }^{2}$ Moreover, the observed links between the skill ratio and skill-specific labor market outcomes affect the relationship between the skill ratio and emigration rates

1. Skilled workers are defined as workers with at least some tertiary education in the population aged more than 25 years. Unemployment rates by skill are constructed using the "key indicators" given by the ILO (International Labour Organization 2009; see the Appendix for a technical description); data on educational attainment are from Barro and Lee (2000). All data are grouped in five-year intervals for the period 1980-2005 and are pooled over time.

2. This statement holds even when relative wages of the skilled decrease, as shown in our model. 


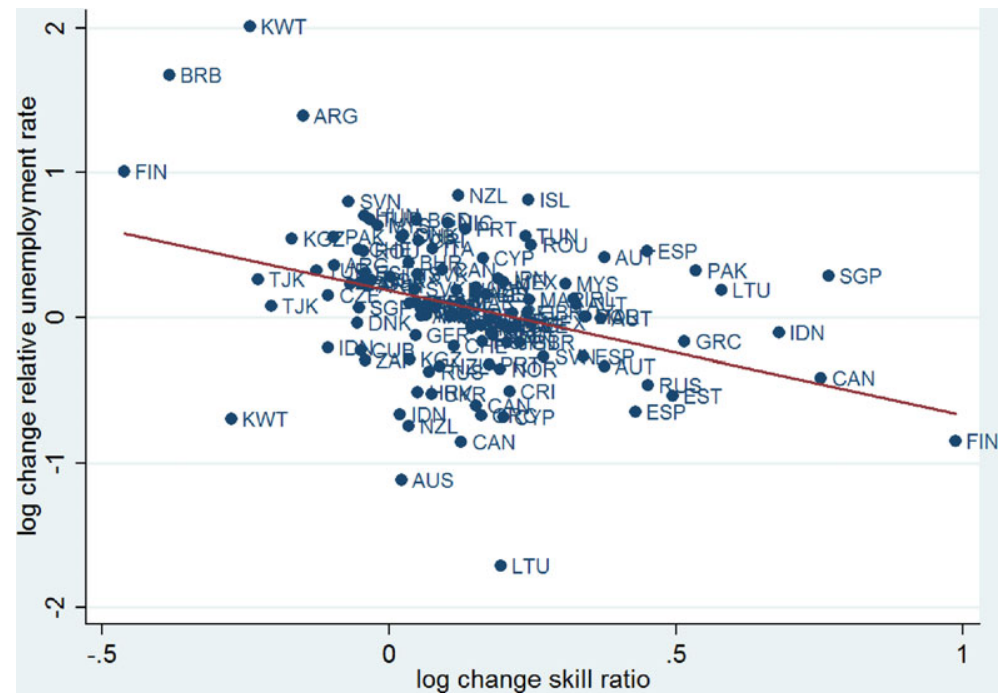

FIGURE 2. Change in skill ratio and change in relative unemployment. The figure shows the simple correlation between the log change of relative unemployment rate of skilled workers and the $\log$ change of skill ratio. The regression coefficient of log skill ratio is -0.86 (robust SE: 0.20 ), with $R$-squared of 0.13. Data are for an unbalanced panel of 75 countries in 5-year intervals from 19802005.

of the skilled and unskilled accordingly: the more skill-abundant countries have a significantly lower emigration rate of skilled to unskilled workers. Figure 3 presents a scatterplot of this so-called brain drain against countries' skill ratios. ${ }^{3}$ Clearly, the more skill-abundant countries suffer much less from brain drain than do skill-scarce ones. In Figure 4 we plot log changes in brain drain against log changes in skill ratio. Once again, we observe that countries that increase their skill ratio tend to experience declining brain drain.

Motivated by these correlations, we build a model of directed technology adoption, skill-specific unemployment, and migration. Toward this end, we combine a version of the canonical model of directed technological change (Acemoglu 1998, 2002; Gancia and Zilibotti 2009) with a model that features matching frictions in the labor market (Mortensen 1970; Pissarides 2000). We show that three conditions are necessary for the skill premium and relative employment rates of skilled workers to be increasing in the skill ratio. First, the elasticity of substitution between skilled and unskilled labor must be sufficiently large. This guarantees that the relative demand for skill rises with the skill ratio as the adoption of technologies complementing the relatively more abundant employed factor becomes more profitable (market size effect). Second, labor markets must be characterized by enough friction that an increase in the skill ratio does not increase relative labor supply by too much. Otherwise, skill premia

3. Data on migration (by skill) to OECD countries are from Beine, Docquier, and Rapoport (2008); the data are for 1990 and 2000. 


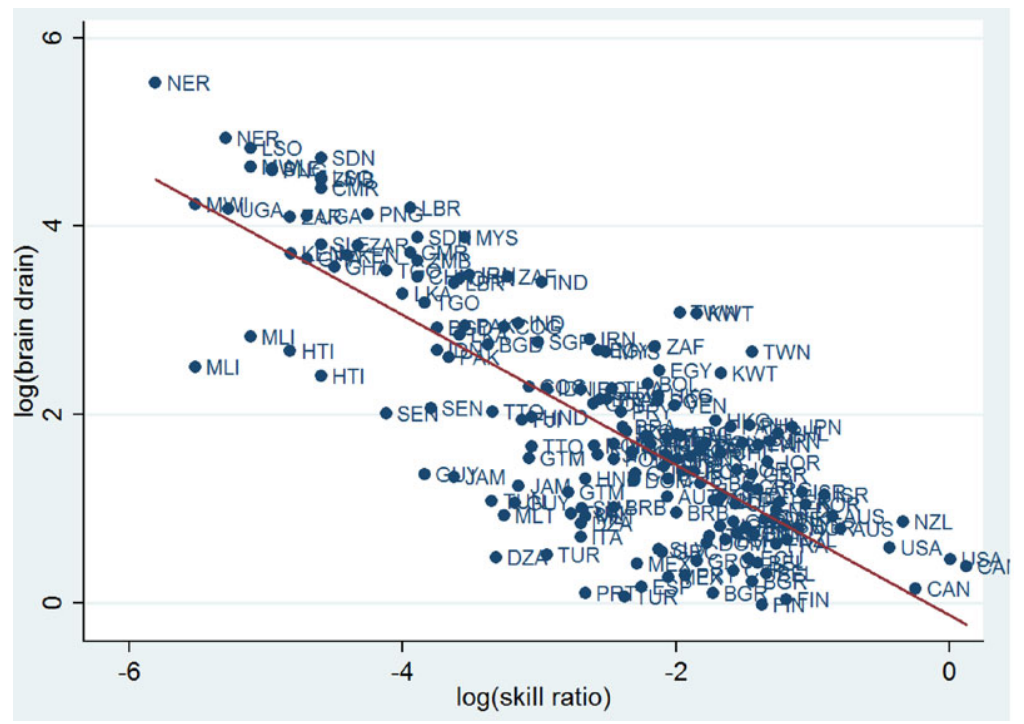

FIGURE 3. Skill ratio and brain drain. The figure shows the simple correlation between the log relative migration rate of skilled workers (brain drain) and the log skill ratio. The regression coefficient of $\log$ skill ratio is -0.796 , (robust SE: 0.06), with $R$-squared of 0.63 . Data are for a sample of 92 countries for 1990 and 2000.

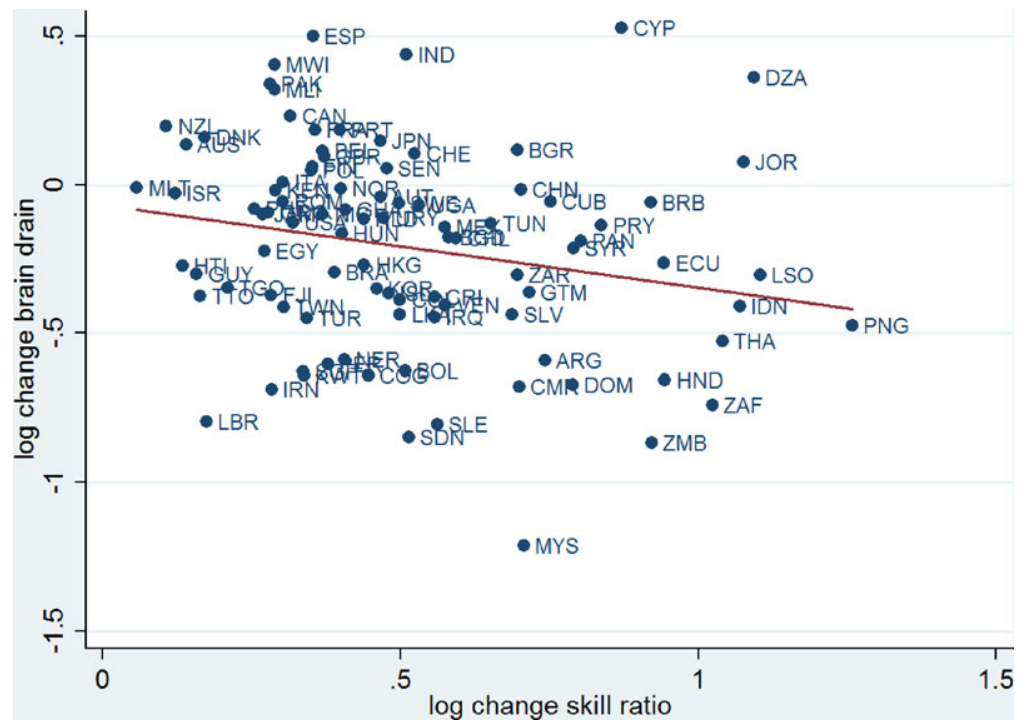

FIGURE 4. Change in skill ratio and change in brain drain. The figure shows the simple correlation between the log change of the relative migration rate of skilled workers (brain drain) and the log change of skill ratio. The regression coefficient of log skill ratio is -0.28 , (robust SE: 0.13 ), with $R$-squared of 0.04. Data are for a sample of 92 countries for 1990 and 2000. 
would have to fall in order to absorb the additional factor supply, leading to relatively lower employment rates of skilled workers and inducing technological change-via the market size effect-that is biased toward the factor that has become relatively more scarce. We also show that, if the matching elasticities are higher, then the more skill-biased technological change manifests itself less as increasing skill premia than as increasing employment opportunities for the skilled. The third necessary condition is that technology barriers across countries must be large enough that domestic skill endowments have an effect on the direction of technology adoption.

We extend the model to include labor market institutions by considering unemployment benefits and firing costs. We show that the presence of such regulations renders our previous conditions-for an increase in the skill ratio to increase the relative employment rate of skilled workers-no longer sufficient. In addition, then, unemployment benefits and firing costs must be sufficiently low; otherwise, an increase in the skill ratio can actually reduce the relative employment rate of skilled workers.

As for predictions about migration, we show that the same conditions guaranteeing that an increase in the skill ratio increases the relative employment rate of skilled workers also ensure that the brain drain is reduced when the skill ratio rises (for sufficiently low levels of the skill ratio). In this case, an increase in the skill ratio-by increasing relative employment rates and wages-also increases the relative expected wages of skilled workers and thereby reduces relative incentives to emigrate.

Finally, we use a calibrated version of our model to show that it performs reasonably well in replicating, both qualitatively and quantitatively, the cross-sectional correlations just described (i.e., the positive relation between skill ratio and relative productivity of skilled workers, the negative relation between skill ratio and relative unemployment of skilled workers, the negative relation between skill ratio and brain drain) as well as the correlation between skill upgrading and reduced brain drain evident during the 1990s. We also demonstrate that, given the skill ratios now prevailing in many developing countries, increases in that ratio could result in further and sizable decreases in the brain drain.

We contribute to the literature in several ways. This paper is the first to introduce search and matching frictions (see Mortensen 1970; Pissarides 2000) into a model of directed technological change (Acemoglu 1998, 2002; Gancia and Zilibotti 2009) in order to examine the effects of the skill ratio on skill-specific labor market outcomes. We are consequently able to study interactions between labor market frictions and directed technological change and provide several interesting results that are new to the literature. Moreover, our predictions can be used to provide new evidence for models of directed technological change. So far, only a few studies have tested this kind of model in a cross-country context. Caselli and Coleman (2006) derive the productivities of skilled and unskilled workers from a cross-section of wage premia and income data by calibrating a reduced-form model of directed technological change. These authors find that the relative productivities of skill are positively correlated with income per worker. Acemoglu and Zilibotti (2001) show that skill-technology mismatch can partially explain cross-country income differences when all countries use the technologies developed by the United States. More recently, Gancia, Müller, and Zilibotti (2011) 
use a full-fledged quantitative model of directed technological change-featuring skill-technology mismatch, technology adoption costs, and international tradethat can endogenously generate skill-specific productivity differences. They estimate technology adoption costs by fitting predicted income per worker to the data and find that their model replicates observed income differences extremely well. However, none of these papers try to match data other than that on income and wages. By focusing on unemployment rates and migration, we provide new evidence that supports models of directed technological change.

We also contribute to the literature on the brain drain, which shows that increases in the skill ratio may coincide with decreases in the brain drain. On the one hand, this relation reflects workers investing more in education when their emigration probability increases. If the net effect on the domestic skill ratio is positive-in other words, if relatively few of the workers that obtain higher education owing to migration factors actually emigrate- then higher-skilled emigration prospects can reduce the brain drain. ${ }^{4}$ According to this strand of the literature, an increase in the migration probability can lead to an increase in human capital in the source country. On the other hand, recent observations indicate that an increase in the source country's human capital can lead to an increase in domestic wages if returns to skilled labor are increasing and thus reduce emigration incentives. That scenario obtains in Grossmann and Stadelmann (2011) and in De la Croix and Docquier (2012), where productivity is assumed to be increasing in skilled labor endowments. Causality in our model also runs from skill ratio to migration; in contrast to the existing literature, however, we look not only at wages but also at unemployment rates as determinants of the brain drain. We do believe that wages are an important determinant of the decision of workers to emigrate, but the probability of their employment is likely to be no less important. ${ }^{5}$ Finally, it is plausible that technology can react more quickly to changes in skill ratios than educational attainment can change in response to exogenous factors that increase the profitability of acquiring skills; this likely difference corroborates the channel of causality emphasized in our paper. ${ }^{6}$

In terms of policy implications, findings reported here suggest that educational policies aiming to increase workforce skills may be even more important than commonly acknowledged. First, public investment in education should (via endogenous technology adjustment) improve the employment prospects of skilled workers while reducing those of unskilled ones. Second, countries facing a deterioration in their skilled workforce due to emigration could reverse that trend by increasing their skill share; doing so would increase demand for skilled labor and

4. In that case, the brain drain becomes a brain gain. See for example Mountford (1997), Stark, Helmenstein, and Prskawetz (1997, 1998), and Beine, Docquier, and Rapoport (2001, 2008).

5. In fact, we find that wage differences are no longer significant once we control for unemployment rates.

6. In our working paper (Fadinger and Mayr 2011) we address the causality issue in reduced-form regressions using instrumental variables. That paper establishes the presence of a channel running from skill ratios to technology, unemployment, and migration. 
thus improve labor market conditions for the skilled at home. But if emigration of the skilled workforce is not met by an adequate policy response, then it could well develop into a vicious cycle as labor market conditions for the skilled deteriorate further and emigration incentives are reinforced.

The rest of this paper is organized as follows. In Section 2, we set up a model of skill-biased technology adoption and unemployment. We first derive the equilibrium without migration for the cases of exogenous and endogenous technology. We then investigate the effect of labor market institutions before extending the model to allow for migration. In Section 3, we calibrate the model and perform several comparative statics exercises; we also show that the model's predictions-about the correlations between our variables of interest-match those observed in the data. Section 4 presents our conclusions.

\section{The Model}

\subsection{Production}

We use a model that features two different types of labor, skilled and unskilled workers, as well as factor-biased (directed) technical progress. This model is based on Acemoglu (1998, 2002) and Gancia and Zilibotti (2009). ${ }^{7}$

The world is modeled as consisting of many countries that all have the same production structure and preferences but may differ in terms of skill endowments. Countries are linked via technology adoption and (later) through migration, but we abstract from international trade. ${ }^{8}$ In each country, final output can be used for consumption, to pay for the fixed cost of innovation, and for the hiring costs of workers in the intermediate sector. The final-output sector is perfectly competitive, and final output is produced according to the aggregate production function

$$
Y=\left[Y_{L}^{\frac{\epsilon-1}{\epsilon}}+Y_{H}^{\frac{\epsilon-1}{\epsilon}}\right]^{\frac{\epsilon}{\epsilon-1}},
$$

where $Y_{L}$ and $Y_{H}$ are sectoral aggregate goods produced with unskilled labor $L$ and skilled labor $H$ (respectively), and $\epsilon>1$ is the elasticity of substitution between them. From the final producer's profit maximization problem we obtain the aggregate inverse demand and the relative inverse demand for sectoral aggregates as follows:

$$
P_{H}=\left[\frac{Y}{Y_{H}}\right]^{\frac{1}{\epsilon}},
$$

7. Although our model is static (for reasons of tractability), the comparative statics of skill endowment effects on technology are the same as the steady-state ones in a dynamic model such as that described by Acemoglu (1998, 2002).

8. We abstract from international trade because it would substantially complicate the model without adding much to our specific mechanism. 


$$
\begin{gathered}
P_{L}=\left[\frac{Y}{Y_{L}}\right]^{\frac{1}{\epsilon}}, \\
{\left[\frac{P_{H}}{P_{L}}\right]=\left[\frac{Y_{L}}{Y_{H}}\right]^{\frac{1}{\epsilon}} .}
\end{gathered}
$$

Here we have assumed that final output is the numéraire, which implies that

$$
P=P_{H}^{1-\epsilon}+P_{L}^{1-\epsilon}=1 .
$$

Sectoral final output is produced under perfect competition using a "constant elasticity of substitution" aggregator over a measure $A_{L}$ (resp., $A_{H}$ ) of sectorspecific differentiated intermediate inputs, $y_{L}(i)$ (resp., $y_{H}(i)$ ), where the elasticity of substitution between varieties is $\sigma>1$ :

$$
Y_{j}=E_{j}\left[\int_{0}^{A_{j}} y_{j}(i)^{\frac{\sigma-1}{\sigma}} d i\right]^{\frac{\sigma}{\sigma-1}}, j \in\{L, H\} .
$$

The range of available intermediate inputs captures the state of technology and will be endogenously determined in equilibrium. The terms $E_{j} \equiv A_{j}^{\frac{\sigma-2}{\sigma-1}}, j \in\{L, H\}$, are externalities that conveniently pin down a degree of increasing returns that makes sectoral production functions linear in $A_{L}$ or $A_{H}$ and thus simplify the algebra. Note that this normalization does not change any of the qualitative implications of the model (see Gancia and Zilibotti 2009).

From the profit maximization problem of sectoral final producers, we obtain the following inverse demand functions for intermediate goods:

$$
p_{j}(i)=y_{j}(i)^{-\frac{1}{\sigma}} Y_{j}^{\frac{1}{\sigma}} P_{j} E_{j}, \quad j \in\{L, H\} .
$$

Producers in the intermediate sectors are monopolistically competitive (because of increasing returns to scale) and use labor in production. Their production technology is given by $y_{L}(i)=l(i)$ and $y_{H}(i)=Z h(i)$, where $l(i)$ is unskilled labor input, $h(i)$ is skilled labor input, and $Z$ is an exogenous productivity shifter.

From the demand functions for intermediates (7) it follows that revenue of intermediate producers in the two sectors is given by

$$
\begin{gathered}
p_{L}(i) y_{L}(i)=Y_{L}^{\frac{1}{\sigma}} l(i)^{\frac{\sigma-1}{\sigma}} P_{L} E_{L}, \\
p_{H}(i) y_{H}(i)=Y_{H}^{\frac{1}{\sigma}}(Z h(i))^{\frac{\sigma-1}{\sigma}} P_{H} E_{H} .
\end{gathered}
$$

Firms in the intermediate sectors face labor market frictions that we model following Helpman and Itskhoki (2010). A firm in the $L(H)$ sector that wants to hire $l(h)$ workers must pay a hiring cost of $b_{L} l\left(b_{H} h\right)$; here $b_{j}, j \in\{H, L\}$, is exogenous to the firm but depends on labor market frictions (to be discussed in what 
follows). Hence workers cannot be replaced without a cost, which makes workers inside the firm different from those outside the firm. So once hired, workers have bargaining power. We assume strategic wage bargaining with equal weights between the firm and its workers à la Stole and Zwiebel (1996a,b). This assumption implies a distribution of revenue according to Shapley values. According to the revenue function (8) the firm gets a fraction $\sigma /(2 \sigma-1)$ of the revenue and workers get a fraction $(\sigma-1) /(2 \sigma-1)$. Then the firm chooses an employment level that maximizes profits, which are given by

$$
\begin{aligned}
\pi_{L}(i) & =\frac{\sigma}{2 \sigma-1} Y_{L}^{\frac{1}{\sigma}} l(i)^{\frac{\sigma-1}{\sigma}} P_{L} E_{L}-b_{L} l(i)-f_{L}, \\
\pi_{H}(i) & =\frac{\sigma}{2 \sigma-1} Y_{H}^{\frac{1}{\sigma}}(Z h(i))^{\frac{\sigma-1}{\sigma}} P_{H} E_{H}-b_{H} h(i)-f_{H} .
\end{aligned}
$$

Producers in the two sectors adopt technologies from the technological frontierwhich we assume to be the state of technology in the United States - at a fixed cost $f_{j}, j \in\{L, H\}$, in terms of the final good. The assumption that countries do not invent technologies independently but rather adopt them from a technology frontier is especially plausible for developing countries yet may also be valid for industrialized countries; it is used, for example, in Caselli and Coleman (2006) and in Acemoglu, Aghion, and Zilibotti (2006). ${ }^{9}$ Following Nelson and Phelps (1966) and Gancia and Zilibotti (2009), among others, we assume that the cost of adopting the technology for a specific variety in a given sector is decreasing in the gap to the technological frontier. Thus $f_{j}=\mu\left(A_{j} / A_{j}^{U S}\right)^{\xi}$ for $j \in\{L, H\}$, where $\mu>0$ and $\xi>0$ is an inverse measure of the barriers to technology adoption. This specification implies that the further behind a country is relative to the frontier in a given sector, the cheaper it is to adopt technologies in that sector.

The solution to this profit maximization problem implies that the optimal employment of firms may be written as

$$
\begin{aligned}
l(i) & =l=\left[\frac{\sigma-1}{2 \sigma-1} \frac{1}{b_{L}} P_{L} E_{L}\right]^{\sigma} Y_{L}, \\
h(i) & =h=\left[\frac{\sigma-1}{2 \sigma-1} Z^{\frac{\sigma-1}{\sigma}} \frac{1}{b_{H}} P_{H} E_{H}\right]^{\sigma} Y_{H},
\end{aligned}
$$

which is decreasing in hiring costs.

Using this together with demand (7) and the production technologies $y_{L}=l$ and $y_{H}=Z h$, we find that optimal prices are given by constant markups over the hiring costs:

$$
p_{L}(i)=p_{L}=\left(\frac{2 \sigma-1}{\sigma-1}\right) b_{L}, \quad p_{H}(i)=p_{H}=\left(\frac{2 \sigma-1}{\sigma-1}\right) \frac{b_{H}}{Z} .
$$

9. For empirical evidence on the importance of technology spillovers, see Coe, Helpman, and Hoffmaister (2009). 
Since wages equal a fraction $(\sigma-1) /(2 \sigma-1)$ of revenue (8) divided by employment (10), we obtain

$$
w_{j}=b_{j}, \quad j \in\{L, H\} .
$$

Note also that given the pricing condition (11) and employment (10), optimal profits can be written as

$$
\pi_{j}=\frac{1}{2 \sigma-1} p_{j} y_{j}-f_{j}, \quad j \in\{L, H\} .
$$

\subsection{Labor Market}

Each country is populated by two types of individuals, who are in fixed supply. There are $H$ skilled workers and $L$ unskilled workers who maximize expected utility from consumption, $U_{j}=E\left(C_{j}\right)$ for $j \in\{H, L\}$, given their expected income. Let $H_{E}\left(L_{E}\right)$ be the aggregate employment of skilled (unskilled) workers. A skilled (unskilled) individual who searches for work finds a job with probability $x_{H}=H_{E} / H$ $\left(x_{L}=L_{E} / L\right)$, where $x_{j}$ measures the degree of labor market tightness in sector $j$. Thus, the skilled (unskilled) worker's income is equal to $x_{H} w_{H}\left(x_{L} w_{L}\right)$.

As in the standard model of job search and unemployment (e.g., Mortensen 1970; Diamond 1981; Pissarides 2000), we assume that firms must post vacancies in order to attract workers. This assumption implies that the cost of hiring, $b_{j}$, depends on labor market tightness. Following Blanchard and Gali (2010) and Helpman and Itskhoki (2010), we assume that

$$
b_{j}=a_{j} x_{j}^{\alpha} \quad \text { for } j \in\{L, H\}, a_{j}>1, \alpha>0,
$$

where $b_{j}$ is the cost of hiring per worker, $a_{j}$ is a measure of frictions in the labor market, ${ }^{10}$ and $\alpha$ is the elasticity of the wage with respect to the employment rate $x$. Using equation (12) together with (14), we obtain a first expression for the wage premium as a function of the relative employment rate of the skilled:

$$
\frac{w_{H}}{w_{L}}=\frac{a_{H}}{a_{L}}\left(\frac{x_{H}}{x_{L}}\right)^{\alpha} .
$$

Following the labor market literature (e.g., Pissarides 2000), we use the term relative wage curve (or relative matching curve) when referring to this relation between the wage premium and relative labor market tightness. This curve is equivalent to the labor supply curve in the presence of matching frictions and is increasing in the relative employment rate of skilled workers; thus, a relatively tighter labor market implies relatively higher wages. Observe that a lower value of $\alpha$, which is equivalent to less frictional labor markets, makes this relation flatter.

10. Higher values of $a_{j}$ correspond to more friction in the labor market. 


\subsection{Exogenous Technology}

We now solve for the equilibrium of the economy while assuming (for the moment) that the level of technology $A_{H}, A_{L}$ is given exogenously.

From the labor market clearing conditions

$$
L_{E}=\int_{0}^{A_{L}} l(i) d i \text { and } H_{E}=\int_{0}^{A_{H}} h(i) d i
$$

we obtain $l(i)=L_{E} / A_{L}$ and $h(i)=H_{E} / A_{H}$. After substituting these into the sectoral production functions (6), we can express sectoral output as

$$
Y_{L}=A_{L} L_{E}, Y_{H}=A_{H} Z H_{E}
$$

and the sectoral relative price according to (4) as

$$
\frac{P_{H}}{P_{L}}=\left[\frac{A_{L} L_{E}}{A_{H} Z H_{E}}\right]^{\frac{1}{\epsilon}} \text {. }
$$

Now we can derive a second expression for the skill premium-for given levels of technology $A_{H}, A_{L}$-by using equations (11), (12), and (16). To do this we note that the revenue of the intermediate sectors equals expenditure on sectoral intermediates (i.e., $p_{L} L_{E}=P_{L} Y_{L}$ and $p_{H} Z H_{E}=P_{H} Y_{H}$ ) and then substitute for prices using (17):

$$
\frac{w_{H}}{w_{L}} \equiv \omega=\frac{P_{H} Z A_{H}}{P_{L} A_{L}}=\left[\frac{Z A_{H}}{A_{L}}\right]^{\frac{\epsilon-1}{\epsilon}}\left[\frac{x_{H}}{x_{L}}\right]^{-\frac{1}{\epsilon}}\left[\frac{H}{L}\right]^{-\frac{1}{\epsilon}} .
$$

We call this relation the relative labor demand curve. According to equation (18) the skill premium is increasing in the relative productivity of the skilled (since $\epsilon>1$ ) but is decreasing in the relative employment rate of skilled workers. Moreover, an increase in the relative supply of skill results in a lower skill premium for given employment rates.

In equilibrium, relative employment unambiguously increases in relative labor supply but relative wages and employment rates decrease. To show this we use equation (15) together with (18), where $A_{H}$ and $A_{L}$ are taken as given, to derive

$$
\begin{aligned}
& \frac{H_{E}}{L_{E}}=\left[\frac{a_{L}}{a_{H}}\left(\frac{H}{L}\right)^{\alpha}\left(\frac{Z A_{H}}{A_{L}}\right)^{\frac{\epsilon-1}{\epsilon}}\right]^{\frac{\epsilon}{\alpha \epsilon+1}}, \\
& \frac{x_{H}}{x_{L}}=\left[\left(\frac{a_{H}}{a_{L}}\right)^{-\epsilon}\left(\frac{H}{L}\right)^{-1}\left(\frac{Z A_{H}}{A_{L}}\right)^{\epsilon-1}\right]^{\frac{1}{\alpha \epsilon+1}}, \\
& \frac{w_{H}}{w_{L}}=\left[\frac{a_{H}}{a_{L}}\left(\frac{H}{L}\right)^{-\alpha}\left(\frac{Z A_{H}}{A_{L}}\right)^{\alpha(\epsilon-1)}\right]^{\frac{1}{\alpha \epsilon+1}} .
\end{aligned}
$$

These equalities lead to the following statement. 


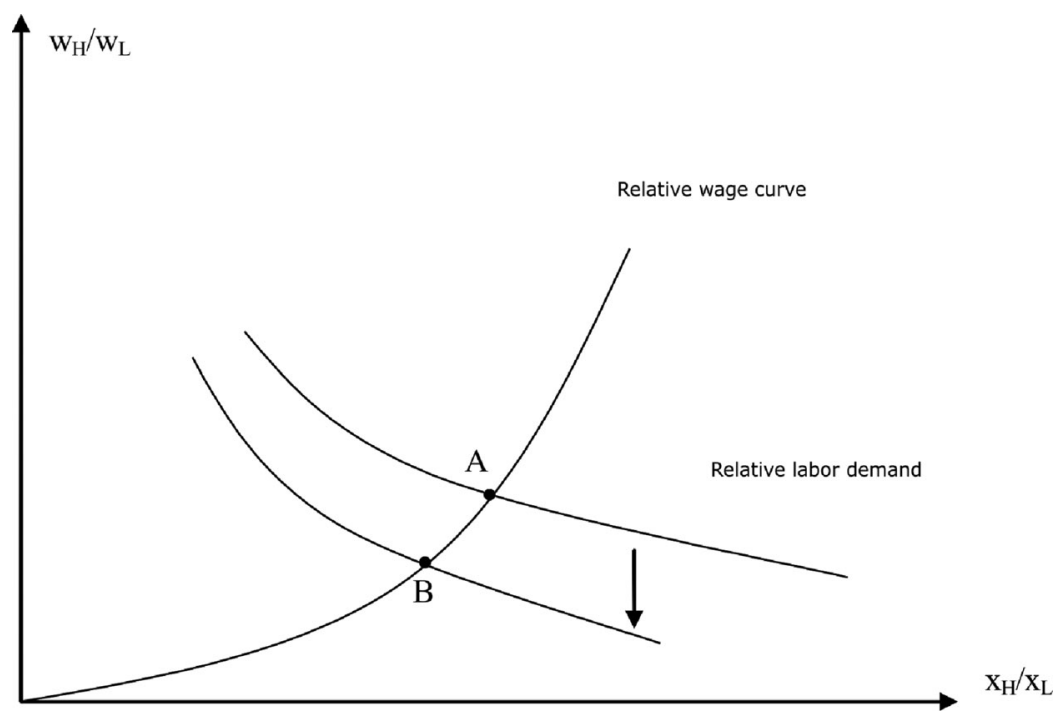

FIGURE 5. Labor market, exogenous technology. The figure depicts the relationship between the skill premium $w_{H} / w_{L}$ and the relative employment rate $x_{H} / x_{L}$ according to (1) relative matching and (2) relative labor demand. If technology is exogenous (or, if technology is skill-biased but $\epsilon<2+\xi$ ), then the labor demand curve is downward-sloping. Then, an increase in the skill ratio $H / L$ leads to an increase in the relative employment of skilled workers, $H_{E} / L_{E}$-compare equation (19)—but a decrease in the relative employment rate and the skill premium via a downward-shift of the labor demand curve (movement from point A to point B)—compare equations (20) and (21).

REMARK 1. Assume that technologies $A_{H}$ and $A_{L}$ are given. Then an increase in the relative number of skilled individuals always results in a decrease in their wage and employment rate relative to the unskilled.

Figure 5 illustrates the labor market equilibrium with exogenous technology. As the relative supply of skilled workers $(H / L)$ increases, the relative labor demand curve (18) shifts downward because, for constant employment rates, the relative wage must fall; in turn, relative labor market tightness is reduced. At the new equilibrium, relatively more skilled are employed than before yet both their (relative) wage and employment rate are now lower.

\subsection{Endogenous Technology}

In this section we allow for free entry into the intermediate sectors so that we can pin down the state of technology $A_{H}, A_{L}$ endogenously.

According to the optimal profit equation (13), free entry implies that intermediate producers make zero profits:

$$
\pi_{j}=\frac{1}{2 \sigma-1} p_{j} j-f_{j}=0, \quad j \in\{L, H\}
$$


Furthermore, we can use the equalities $p_{L} L_{E}=P_{L} Y_{L}$ and $p_{H} Z H_{E}=P_{H} Y_{H}$ together with labor market clearing $L_{E}=A_{L} l$ and $H_{E}=A_{H} h$, sectoral output (16), relative prices (17), and the expressions for the cost of technology adoption to write the ratio of the free entry conditions as

$$
\frac{\pi_{H}}{\pi_{L}}=\frac{P_{H} Z H_{E}}{P_{L} L_{E}}=\left(\frac{A_{H}}{A_{L}}\right)^{-\frac{1}{\epsilon}}\left(\frac{Z H_{E}}{L_{E}}\right)^{\frac{\epsilon-1}{\epsilon}}=\left(\frac{A_{H} / A_{L}}{A_{H}^{U S} / A_{L}^{U S}}\right)^{\xi} .
$$

This expression (23) shows that relative profitability has two components, which act in opposite directions: a "price effect", whereby profits are higher within sectors that produce more expensive goods; and a "market size effect", whereby profits are higher in sectors that employ more workers.

Solving for relative technologies, we obtain

$$
\frac{A_{H}}{A_{L}}=\left(\frac{Z H_{E}}{L_{E}}\right)^{\frac{\epsilon-1}{1+\epsilon \xi}}\left(\frac{A_{H}^{U S}}{A_{L}^{U S}}\right)^{\frac{\epsilon \xi}{1+\epsilon \xi}}
$$

Thus, for finite values of $\xi$, technology is biased toward the employed factor that is relatively more abundant-provided the elasticity of substitution between factors exceeds unity (i.e., factors are gross substitutes). In this case, a fall in the relative price of the skilled aggregate good increases the relative expenditure on that good (i.e., the market size effect dominates the price effect), which makes technology adoption in that sector more profitable. Note also that, as $\xi \rightarrow \infty$ (technology adoption becomes costless), the technological bias equals that of the frontier and is independent of domestic employment. At the other extreme, if $\xi=0$ (technology adoption costs are prohibitive), then the technological bias is independent of the frontier and instead is determined only by the domestic relative employment of skilled workers.

Substituting (24) into the expression for the skill premium (18) yields an expression for the skill premium as a function of relative employment when technology adoption is endogenous:

$$
\frac{w_{H}}{w_{L}}=Z^{\frac{(\epsilon-1)(1+\xi)}{1+\epsilon \xi}}\left(\frac{x_{H} H}{x_{L} L}\right)^{\frac{\epsilon-2-\xi}{1+\epsilon \xi}}\left(\frac{A_{H}^{U S}}{A_{L}^{U S}}\right)^{\frac{\xi(\epsilon-1)}{1+\epsilon \xi}}
$$

Hence the skill premium with endogenous technology is increasing in the relative employment rate of skilled workers as long as $\epsilon>2+\xi$. This means that sectoral aggregates must be sufficiently substitutable for the skill premium to increase in relative employment rates; in that case, the indirect positive effect of the skill ratio on the skill premium via increased relative productivity of skilled workers (technology effect) dominates the direct negative supply effect (see equation (18)). Moreover, an increase in the relative supply of skilled workers shifts the relative demand for skill upward and increases the skill premium for given employment rates as long as $\epsilon>2+\xi$. 
In equilibrium, we obtain expressions for relative employment and employment rates as functions of relative endowments by substituting (24) into (19), (20), and (21):

$$
\begin{aligned}
& \frac{H_{E}}{L_{E}}=\left[Z^{\left.\frac{(\epsilon-1)(1+\xi)}{(1+\epsilon \xi)} \frac{a_{L}}{a_{H}}\left(\frac{H}{L}\right)^{\alpha}\left(\frac{A_{H}^{U S}}{A_{L}^{U S}}\right)^{\frac{\xi(\epsilon-1)}{(1+\epsilon \xi)}}\right]^{\frac{(1+\epsilon \xi)}{\alpha(1+\epsilon \xi)-(\epsilon-2-\xi)}},}\right. \\
& \frac{x_{H}}{x_{L}}=\left[Z^{(\epsilon-1)(1+\xi)}\left(\frac{a_{L}}{a_{H}}\right)^{1+\epsilon \xi}\left(\frac{H}{L}\right)^{\epsilon-2-\xi}\left(\frac{A_{H}^{U S}}{A_{L}^{U S}}\right)^{\xi(\epsilon-1)}\right]^{\frac{1}{\alpha(1+\epsilon \xi)-(\epsilon-2-\xi)}}, \\
& \frac{w_{H}}{w_{L}}=\left[Z^{\alpha(\epsilon-1)(1+\xi)}\left(\frac{a_{L}}{a_{H}}\right)^{\epsilon-2-\xi}\left(\frac{H}{L}\right)^{\alpha(\epsilon-2-\xi)}\left(\frac{A_{H}^{U S}}{A_{L}^{U S}}\right)^{\alpha \xi(\epsilon-1)}\right]^{\frac{1}{\alpha(1+\epsilon \xi)-(\epsilon-2-\xi)}} .
\end{aligned}
$$

Relative wages and relative employment rates are increasing in relative endowments of workers provided $2+\xi<\epsilon<(2+\xi+\alpha) /(1-\alpha \xi)$. This relation can be explained as follows. First, relative wages are increasing in relative employment rates if the relative labor demand function (25) is increasing (i.e., if $\epsilon>2+\xi$ ). The reason is that, even though sectoral prices decrease with sector size (price effect)—which implies lower revenues and lower wages - the technology improves with sector size (market size effect) and revenue and wages increase (given $\epsilon>1$ ). When $\epsilon>2+\xi$, the technology effect is strong enough to make the overall labor demand curve upward sloping. Second, by the matching function (15), relative wages are also increasing in relative employment rates. Matching frictions imply that firms need to pay higher wages as the number of those in employment increases (and the more so the greater is $\alpha$ ) because labor market tightness increases. We therefore state the following proposition.

PROPOSITION 1. With endogenous technologies, an increase in the relative number of skilled workers results in an increase in their wage and employment rate relative to unskilled workers if $2+\xi<\epsilon<(2+\xi+\alpha) /(1-\alpha \xi)$; otherwise, it leads to a decrease.

Let us now examine more closely the labor market effects of an increase in the relative supply of skilled workers, $H / L$. Consider first the case where $\epsilon<2+\xi$. Then the labor demand curve is downward sloping and an increase in $H / L$ shifts it down, so the situation is as in Figure 5: both the skill premium and the relative employment rate of skilled workers decrease.

Now consider the more interesting case of $\epsilon>2+\xi$. Here the labor demand curve is upward sloping and an increase in $H / L$ shifts it up. The overall effect on relative wages and employment rates depends on whether wages increase more strongly with employment according to relative matching (15) or labor demand (25) in other words, whether the relative wage curve (15) crosses relative labor demand 

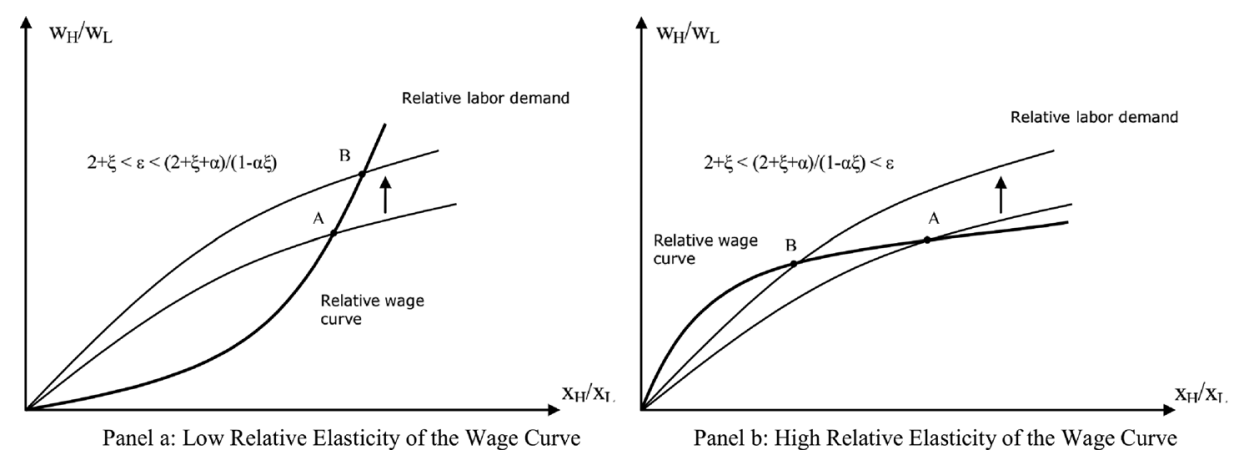

FIGURE 6. Labor market, endogenous technology. The figure depicts the same relations as Figure 5. However, the relative labor demand curve is now upward-sloping, which is the case if technology is skill-biased and $\epsilon>2+\xi$. Now, the effect of an increase in the skill ratio $H / L$ depends on the elasticity of matching, $1 / \alpha$, relative to the elasticity of labor demand, $(1+\epsilon \xi) /(\epsilon-2-\xi)$. If the matching elasticity is relatively low (panel a), we expect an increase in the skill ratio of those in employment, the relative employment rate of skilled workers and the skill premium via an upwardshift of the labor demand curve (movement from point A to point B). If the matching elasticity is relatively high (panel b), we expect a decrease in the skill ratio of those in employment, the relative employment rate of skilled workers and the skill premium. Compare equations (26)-(28).

(25) from below (Figure 6, panel a) or above (panel b). In the first case, where $\epsilon<(2+\xi+\alpha) /(1-\alpha \xi)$ (i.e., labor demand is relatively elastic compared to the wage curve $\left.{ }^{11}\right)$, relative wages and employment of skilled workers increase. But in the second case, where $\epsilon>(2+\xi+\alpha) /(1-\alpha \xi)$ (labor demand is relatively inelastic), relative wages and employment of skilled workers decrease. The intuition is as follows. If $\alpha$ is small compared to $\epsilon$, so that labor markets have small matching frictions and an increase in the relative labor market tightness has little effect on wages, and if the labor demand curve is relatively steep, so that a given change in the wage premium has little effect on relative employment, then the following situation arises: the additional workers are efficiently channeled to employment, but labor demand does not react strongly enough to absorb the increased supply. Hence the skill premium will drop, reducing the relative employment rate of skilled workers. Moreover, since the relative number of those in employment decreases, technology adjusts away from skilled and toward unskilled workers.

We remark that the conditions for the skill premium to be increasing in the skill ratio are more stringent here than in models of directed technological change without unemployment. In, for example, Acemoglu (1998, 2002), $\epsilon>2$ is the only relevant condition in the canonical model of directed technological change, where each country develops its own technologies $(\xi=0)$; for $\xi=0$, our conditions boil down to $2<\epsilon<2+\alpha$. In the case of technology adoption, the condition for an upward-sloping labor demand $(\epsilon>2+\xi)$ is more likely to be fulfilled the greater is

11. The elasticity of labor demand is given by $(1+\epsilon \xi) /(\epsilon-2-\xi)$ according to equation (25), and the elasticity of the wage curve is given by $1 / \alpha$ according to equation (15). 
the cost of technology adoption (smaller $\xi$ ), because then the effect of an increase in home-country skill endowments on domestic technology is greater. However, the second condition $\epsilon<(2+\xi+\alpha) /(1-\alpha \xi)$ is more likely to be fulfilled for smaller costs of adoption (greater $\xi$ ) as labor demand becomes more elastic.

Finally, observe that the relative size of the wage and employment response depends also on the elasticities of the wage curve and labor demand. As $\alpha$ tends to infinity (extremely inelastic labor supply), the wage curve becomes vertical; then any adjustment in response to increased skill supply occurs through the skill premium, which increases while employment rates are unaffected. In this case, for $\xi=0$ the model is equivalent to one with an exogenous labor supply (Acemoglu 1998, 2002). In contrast, if $\alpha$ tends to zero (extremely elastic labor supply) then the wage curve becomes horizontal; now all adjustment occurs through the relative employment rate, which decreases with no effect on the skill premium.

\subsection{Labor Market Institutions}

We now introduce unemployment benefits and firing costs into the model. For simplicity, we set $\xi=0$ here so that the barriers to technology adoption are prohibitive and the technological bias depends only on domestic skill endowments. We follow Helpman and Itskhoki (2007) in modeling labor market frictions, and we assume that unemployment benefits and firing costs are the same for skilled and unskilled workers. Let $b_{u}$ denote unemployment benefits, which is the income of workers who do not find a job, and let $b_{f}$ denote firing costs, which is a transfer to workers who are matched but then fired. We assume that matched workers become unsuitable for the job with probability $\delta$, in which case they are fired. Therefore, a firm that needs $j$ employees must recruit $j /(1-\delta)$ workers and bears a search cost of $a_{j} x_{j}^{\alpha} j /(1-\delta)$. In addition, since the firm fires a fraction $\delta$ of hired workers, it faces a firing cost of $b_{f} \delta j /(1-\delta)$.

We consider a firm in sector $j$ that has $j$ employees after recruiting and firing; its revenue is given by equation (8). We assume that each worker who is fired receives unemployment benefits $b_{u}$. As before, we follow Stole and Zwiebel (1996a,b) in assuming that the marginal surplus of each worker is equally divided between the worker and the firm. If $w_{j}(j)$ is the equilibrium wage rate as a function of employment, then this implies the following split of revenues: ${ }^{12}$

$$
\frac{\partial}{\partial j}\left[Y_{j}^{1 / \sigma}(Z j)^{\frac{\sigma-1}{\sigma}} P_{j} E_{j}-w_{j}(j) j\right]=w_{j}(j)-b_{u} .
$$

The left-hand side of this expression is the marginal gain of the firm from employing an additional worker, a value that accounts for the effect of this worker's departure on the wage rate of remaining workers. The right-hand side is the worker's marginal gain from being employed, which is given by the difference between the wage rate and the unemployment benefit. We thus have a differential equation with the following

$\overline{12 .}$ The $Z$ equals 1 when $j=l(L)$ in the following. 
solution: ${ }^{13}$

$$
w_{j}(j)=\frac{\sigma-1}{2 \sigma-1} \frac{Y_{j}^{1 / \sigma}(Z j)^{\frac{\sigma-1}{\sigma}} P_{j} E_{j}}{j}+\frac{1}{2} b_{u} .
$$

Therefore, wages are equal to a fraction $(\sigma-1) /(2 \sigma-1)$ of revenues divided by the number of employees plus half of the outside option. Hence the firm receives the remaining share $\sigma /(2 \sigma-1)$ of revenues minus half of the workers' total unemployment benefits. The firm then chooses the employment level that maximizes profits, which is given by

$$
\max _{j} \frac{\sigma}{2 \sigma-1} Y_{j}^{1 / \sigma}(Z j)^{\frac{\sigma-1}{\sigma}} P_{j} E_{j}-b_{j} j-\mu
$$

here the hiring costs per worker are

$$
b_{j}=\frac{1}{2} b_{u}+\frac{b_{f} \delta}{(1-\delta)}+\frac{a_{j} x_{j}^{\alpha}}{(1-\delta)} .
$$

This problem's first-order condition can be solved to yield optimal employment, which is given by

$$
j=\left[\frac{\sigma-1}{2 \sigma-1} Z^{\frac{\sigma-1}{\sigma}} P_{j} E_{j}\left(b_{j}\right)^{-1}\right]^{\sigma} Y_{j} .
$$

Each firm's employment level is increasing in the sectoral price index $P_{j}$ and in sector size $Y_{j}$ but is decreasing in hiring costs $b_{j}$. Note that optimal prices are given by $p_{j}=(2 \sigma-1) b_{j} /(\sigma-1) Z$. Finally, the expression for optimal employment implies that $w_{j}=b_{j}+b_{u} / 2$.

From the expression for hiring costs $b_{j}$ and the relation between wages and hiring costs, we again derive the relative matching function (wage curve):

$$
\frac{w_{H}-\frac{1}{2} b_{u}}{w_{L}-\frac{1}{2} b_{u}}=\frac{\frac{1}{1-\delta}\left(a_{H}\left(\frac{H_{E}}{H}\right)^{\alpha}+\delta b_{f}\right)+\frac{1}{2} b_{u}}{\frac{1}{1-\delta}\left(a_{L}\left(\frac{L_{E}}{L}\right)^{\alpha}+\delta b_{f}\right)+\frac{1}{2} b_{u}} .
$$

We can then use the relative demand for sectoral aggregate goods (17), the fact that $p_{j}=P_{j} A_{j}$, the relation (24) between relative technologies from the free-entry conditions, the expression for optimal prices, and the relation between wages and hiring costs to derive the relative inverse demand for skilled workers:

$$
\frac{w_{H}-\frac{1}{2} b_{u}}{w_{L}-\frac{1}{2} b_{u}}=Z^{\epsilon-2}\left(\frac{H_{E}}{L_{E}}\right)^{\epsilon-2} .
$$

The free-entry conditions can now be used to derive expressions for $H_{E}$ and $L_{E}$ as functions of relative employment rates. In the skilled sector, the condition $\Pi_{H}=0$

13. This claim can be verified by substituting (30) into (29). 
implies that

$$
\frac{1}{2 \sigma-1} Z P_{H} H_{E}-\mu=0
$$

which can be solved for

$$
\begin{aligned}
H_{E} & =(2 \sigma-1) \mu Z^{-1}\left[1+\left(\frac{P_{H}}{P_{L}}\right)^{\epsilon-1}\right]^{-\frac{1}{\epsilon-1}} \\
& =(2 \sigma-1) \mu Z^{-1}\left[1+\left(\frac{Z x_{H}}{x_{L}}\right)^{1-\epsilon}\left(\frac{H}{L}\right)^{1-\epsilon}\right]^{-\frac{1}{\epsilon-1}} .
\end{aligned}
$$

Similarly,

$$
L_{E}=(2 \sigma-1) \mu\left[1+\left(\frac{Z x_{H}}{x_{L}}\right)^{\epsilon-1}\left(\frac{H}{L}\right)^{\epsilon-1}\right]^{-\frac{1}{\epsilon-1}} .
$$

Then, combining equations (32) and (33) and using the expressions just given for $H_{E}$ and $L_{E}$, we can derive the following implicit equation for the equilibrium relative employment rate of the skilled:

$$
\begin{aligned}
Z^{\epsilon-1}\left[\frac{1+\left(\frac{Z x_{H}}{x_{L}}\right)^{1-\epsilon}\left(\frac{H}{L}\right)^{1-\epsilon}}{1+\left(\frac{Z x_{H}}{x_{L}}\right)^{1-\epsilon}\left(\frac{H}{L}\right)^{1-\epsilon}}\right]^{\frac{\epsilon-2}{1-\epsilon}} \\
=\frac{\frac{1}{1-\sigma}\left[\frac{a_{H}(2 \sigma-1)^{\alpha} \mu^{\alpha}}{(Z H)^{\alpha}}\left(1+\left(\frac{Z x_{H}}{x_{L}}\right)^{1-\epsilon}\left(\frac{H}{L}\right)^{1-\epsilon}\right)^{\frac{\alpha}{1-\epsilon}}+\delta b_{f}\right]+\frac{1}{2} b_{u}}{\frac{1}{1-\sigma}\left[\frac{a_{L}(2 \sigma-1)^{\alpha} \mu^{\alpha}}{L^{\alpha}}\left(1+\left(\frac{Z x_{H}}{x_{L}}\right)^{\epsilon-1}\left(\frac{H}{L}\right)^{\epsilon-1}\right)^{\frac{\alpha}{1-\epsilon}}+\delta b_{f}\right]+\frac{1}{2} b_{u}} .
\end{aligned}
$$

Because this equation cannot be solved analytically, we rely on simulations to establish the comparative statics effects of an increase in the skill ratio. Figure 7 plots the relative employment rate of skilled workers $x_{H} / x_{L}$, the skill premium $w_{H} / w_{L}$, and the relative productivity of skill $A_{H} / A_{L}$, as a function of the skill ratio for different levels of unemployment benefits when $2<\epsilon<2+\alpha .{ }^{14}$ We set $\epsilon=2.25$ and $\alpha=1.17^{15}$ and consider three levels of unemployment benefits: $b_{u} \in\{0,0.2,0.25\}$. The figure reveals that, if unemployment benefits are zero (solid line), then not only relative employment rates but also skill premia and relative productivity are unambiguously increasing in the skill ratio. Yet for positive unemployment benefits ( $b_{u}=0.2$, dashed line; $b_{u}=0.25$, dashed-dotted line), the relation is nonmonotonic:

14. For $\epsilon<2$ or $\epsilon>2+\alpha$, the qualitative implications of the model are not affected by the introduction of labor market regulations.

15. For the choice of parameter values see Section 3.1 on calibration. 

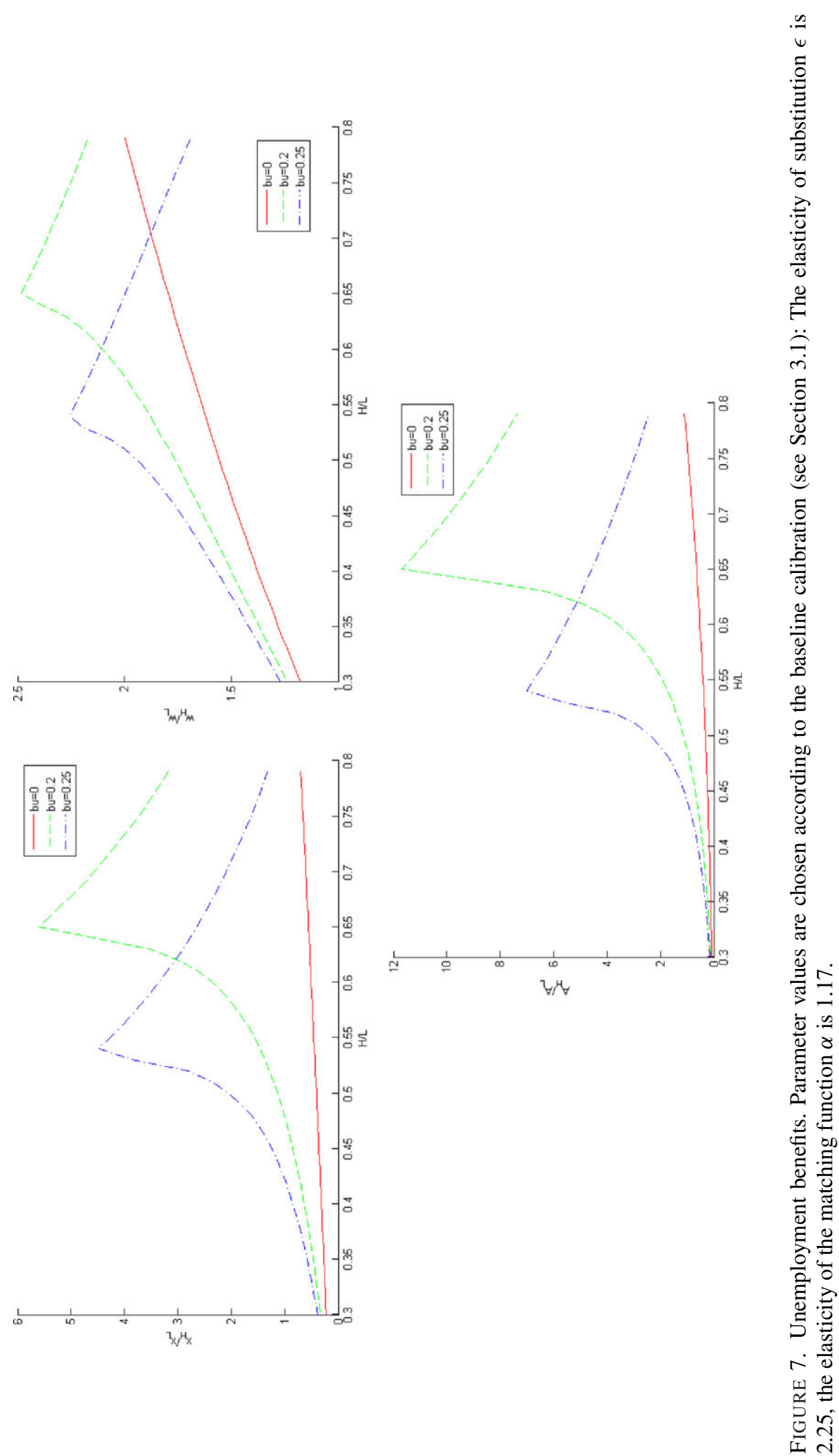
relative employment rates, skill premia, and relative productivity are increasing in the skill ratio for low levels of the skill ratio up to a threshold, whereupon the pattern reverses and those three variables begin to decline in the skill ratio. We remark that the threshold level of the skill ratio is decreasing in the unemployment benefit, so the decrease starts sooner the higher is that benefit. Hence we expect that an increase in the skill ratio increases the relative employment rate of skilled workers when unemployment benefits are low but has the opposite effect for sufficiently high unemployment benefits.

How can we explain the nonmonotonic relationship between relative employment rates, wage premia, technology, and the skill ratio in the presence of unemployment benefits? Initially, as the skill ratio rises, wages and employment rates of skilled workers rise; then, as technology adjusts endogenously (increasing the relative productivity of skilled workers), both the wages and employment of unskilled workers fall with the decline in their relative productivity. At some point, however, unskilled wages are near the unemployment benefit and thus cannot fall further-given that wages equal half of the unemployment benefit plus the expression related to labor market tightness (see previous discussion). Note also that any reduction in employment or exit by firms from the unskilled sector would reduce profits ${ }^{16}$ and, therefore, wages. ${ }^{17}$ Since wages and profits in the unskilled sector cannot fall further, it follows that an increase in $H$ at this point must be associated with an increase in employment in the unskilled sector. That increase induces an endogenous adjustment of technology toward increasing the productivity of the unskilled, which in turn increases unskilled wages and employment rates via higher demand for unskilled workers.

The impact of firing costs is qualitatively the same as that of unemployment benefits, as we verify in unreported simulations. This can be seen from equation (34), wherein (up to a scaling factor) firing costs and unemployment benefits enter the same way. As a consequence, changes in the unemployment benefit or the firing cost can alter the skill ratio's relation to the direction of technological change, relative employment rates, and skill premia. In countries with highly regulated labor markets, an increase in the skill ratio may not trigger skill-biased technological change and therefore will lead to an (otherwise expected) decrease in the skill premium and in the relative employment rate of skilled workers. ${ }^{18}$

\subsection{Migration}

In this section we augment our model with endogenous migration, which generates additional predictions that we can use to test models of directed technological change.

16. Because (a) profits in the unskilled sector equal $\Pi_{L}=P_{L} L_{E}-\mu$ and (b) the market size effect is stronger than the price effect whenever $\epsilon>1$.

17. Because (a) profits are proportional to revenue and (b) wages are a fraction of revenue plus half the unemployment benefit.

18. Fadinger and Mayr (2011) provide evidence that labor market regulation does affect the direction of technological change in the way suggested by our model. 
We consider migration from a given source country to an OECD (Organisation for Economic Co-operation and Development) country, and we treat the OECD as a single country with given expected wages that are not affected by migration from developing countries. Thus, countries are now linked both through technology adoption from the frontier and through migration, but our "small economy" assumption suffices to pin down each country's equilibrium conditions individually. As for the labor market, we use the basic model (without unemployment benefits and firing costs) for ease of exposition.

For individual $k$ of skill type $j$, let the utility associated with migration to the OECD countries be given by

$$
U_{j}^{M}(k)=w_{j}^{\mathrm{OECD}} x_{j}^{\mathrm{OECD}}-c_{j}-\varepsilon(k), j \in\{H, L\} .
$$

Here $w_{j}^{\mathrm{OECD}} x_{j}^{\mathrm{OECD}}$ is the expected wage in the OECD, $c_{j}$ is a deterministic and skillspecific cost of migration to the OECD in terms of utility, and $\varepsilon(k)$ is a stochastic and individual-specific migration cost. Let the utility associated with staying in the country of origin be given by

$$
U_{j}^{S}=w_{j} x_{j}, j \in\{H, L\} .
$$

Then the probability of emigration for a skilled (unskilled) worker can be written as the probability that the stochastic migration cost is low enough that the expected wage in the OECD (adjusted for the deterministic part of migration costs) is greater than the expected wage in the country of origin:

$$
\operatorname{Pr}\left(U_{j}^{M}(k)>U_{j}^{S}\right)=\operatorname{Pr}\left(\varepsilon<w_{j}^{\mathrm{OECD}} x_{j}^{\mathrm{OECD}}-w_{j} x_{j}-c_{j}\right), j \in\{H, L\} .
$$

If we assume that migration costs are logistically distributed ${ }^{19}$ with zero mean and unit variance, the migration rate for skill type $j$ is then

$$
s_{j}=\operatorname{Pr}\left(U_{j}^{M}(k)>U_{j}^{S}\right)=\frac{1}{1+\exp \left[-\left(w_{j}^{\mathrm{OECD}} x_{j}^{\mathrm{OECD}}-w_{j} x_{j}-c_{j}\right)\right]}, j \in\{H, L\} .
$$

In the case of endogenous technology, we substitute for expected wages $w_{H} x_{H}$ and $w_{L} x_{L}$ as functions of $s_{H}$ and $s_{L}$ (respectively) as follows. According to the matching function (14), wages of the skilled and unskilled workers can be expressed as

$$
w_{H}=a_{H}\left[\frac{H_{E}}{\left(1-s_{H}\right) H}\right]^{\alpha}, w_{L}=a_{L}\left[\frac{L_{E}}{\left(1-s_{L}\right) L}\right]^{\alpha} .
$$

19. Assuming a logistic distribution of migration costs is standard practice in models of migration (see Grogger and Hanson 2011; or De la Croix and Docquier 2012) and also results in a good fit to our data (see footnote 27). 
Substituting for $H_{E}$ and $L_{E}$ and using the free-entry conditions (13) yields

$$
\begin{aligned}
& \pi_{H}=\left(\frac{1}{2 \sigma-1}\right) Z P_{H} H_{E}-\mu\left(\frac{A_{H}}{A_{H}^{U S}}\right)^{\xi}=0, \\
& \pi_{L}=\left(\frac{1}{2 \sigma-1}\right) P_{L} L_{E}-\mu\left(\frac{A_{L}}{A_{L}^{U S}}\right)^{\xi}=0 .
\end{aligned}
$$

Here we have substituted for $p_{H} y_{H}$ and $p_{L} y_{L}$ by first using the intermediate production functions $y_{H}=Z h$ and $y_{L}=l$ and then using the equalities $p_{H} h=$ $P_{H} Y_{H} / Z A_{H}=P_{H} H_{E}$ and $p_{L} l=P_{L} Y_{L} / A_{L}=P_{L} L_{E}$.

We substitute for $A_{H}$ and analogously for $A_{L}$ via the equalities $p_{H} Z H_{E}=$ $P_{H} Y_{H}$ and $p_{H} Z=(2 \sigma-1) w_{H} /(\sigma-1)$ derived from the wage expression (12) together with (11). Then, we use the optimal price index (5) to substitute for

$$
P_{H}=\left[1+\left(P_{H} / P_{L}\right)^{\epsilon-1}\right]^{\frac{1}{\epsilon-1}}
$$

and analogously for $P_{L}$. We further substitute for the sectoral relative price $P_{H} / P_{L}$ using (17) together with relative technologies (24) and relative employment (26).

Hence, we can now rewrite wages $w_{H}$ and $w_{L}$ and employment rates $x_{H}$ and $x_{L}$ to express expected wages as functions of the emigration rates $s_{H}$ and $s_{L}:{ }^{20}$

$$
\begin{aligned}
& w_{H} x_{H}=a_{H}\left[\left(\frac{\mu a_{H}^{\xi}(2 \sigma-1)^{1+\xi}}{Z\left(1-s_{H}\right) H(\sigma-1)^{\xi} A_{H}^{U S \xi}}\right)^{\frac{1}{1-\alpha \xi}}(1+A)^{-\frac{(1+\xi)}{(\epsilon-1)(1-\alpha \xi)}}\right]^{1+\alpha}, \\
& w_{L} x_{L}=a_{L}\left[\left(\frac{\mu a_{L}^{\xi}(2 \sigma-1)^{1+\xi}}{\left(1-s_{L}\right) L(\sigma-1)^{\xi} A_{L}^{U S \xi}}\right)^{\frac{1}{1-\alpha \xi}}\left(1+A^{-1}\right)^{-\frac{(1+\xi)}{(\epsilon-1)(1-\alpha \xi)}}\right]^{1+\alpha}
\end{aligned}
$$

where

$$
A \equiv Z^{\frac{(1+\alpha)(1+\xi)(1-\epsilon)}{\alpha(1+\epsilon \xi)-(\epsilon-2-\xi)}}\left(\frac{a_{L}}{a_{H}}\left(\frac{\left(1-s_{H}\right) H}{\left(1-s_{L}\right) L}\right)^{\alpha}\right)^{-\frac{(\epsilon-1)(1+\xi)}{\alpha(1+\epsilon \xi)-(\epsilon-2-\xi)}}\left(\frac{A_{H}^{U S}}{A_{L}^{U S}}\right)^{-\frac{\xi(\epsilon-1)(1+\alpha)}{\alpha(1+\epsilon \xi)-(\epsilon-2-\xi)}} .
$$

Substituting (36) and (37) into the migration equations (35), we obtain two equations in $s_{H}$ and $s_{L}$. These equations cannot be solved analytically, but they offer some intuition. Suppose the skilled migration rate increases above its equilibrium value. On the one hand, this reduces expected wages because a decrease in skill endowments leads to an endogenous adjustment of technology and thus of demand for skills, which further increases incentives for emigration (term in first brackets in the definition of A).

20. Separate expressions for employment rates and wages are given in the Appendix. 
On the other hand, for $\alpha \xi<1$-which is implied by the condition $2+\xi<\epsilon<(2+$ $\xi+\alpha) /(1-\alpha \xi)$-an increase in skilled migration increases expected wages owing to the increase in labor market tightness (first term in square brackets). Overall, this second effect-which amounts to a negative scale effect-dominates whenever the skilled migration rate is too far above its equilibrium value. ${ }^{21}$ Whereas the first effect reinforces migration incentives and suggests multiplicity of equilibria, as found in Grossmann and Stadelmann (2011) and De la Croix and Docquier (2012), the second effect guarantees that the equilibrium is unique, as confirmed by our simulations in the next section. ${ }^{22}$

\section{Simulation of Unemployment Rates and Brain Drain}

\subsection{Calibration and Data}

We now describe the choice of parameter values that are used to simulate the model with migration. A key parameter in our model is the elasticity of substitution $\epsilon$ between skilled and unskilled workers. Gancia, Müller, and Zilibotti (2011) calibrate $\epsilon$ simultaneously together with $Z$, the factor determining the exogenous part of the relative productivity of skilled workers. They use a version of equation (25) without unemployment to fit the evolution of the US skill premium (for $\xi=0$, since the United States is assumed to be the technology frontier), which is defined as the relative wage of college graduates to non-college graduates between 1970 and 2000; they calibrate $\epsilon=2.25$ and $Z=1.96$. Our baseline calibration therefore uses $\epsilon=2.25$ to match this. Note that this value is somewhat larger than that of the short-run elasticity between skilled and unskilled labor found by other studies; for instance Ciccone and Peri (2006) provide estimates for this parameter in the interval [1.4, 2]). ${ }^{23}$ Hence we also consider alternative values for $\epsilon \in\{1.75,2.1,2.5\}$ in robustness checks. We set $Z=1.96$ throughout our simulations.

Another important parameter is $\alpha$, the elasticity of the matching function. This parameter is related to the elasticity of the standard Cobb-Douglas matching function with respect to vacancies for which many estimates are available via the relation $\alpha=(1-\eta) / \eta .^{24}$ The estimates for this parameter differ substantially across studies

21. As $s_{H}$ tends to unity, the first term tends to infinity.

22. The mechanism that here leads to uniqueness does not depend on specific assumptions about the distribution of migration costs but instead results from labor market frictions. In addition, the stochastic migration cost implies that there is always a sufficient mass of individuals who do not find it profitable to migrate. Computationally, we find that the equilibrium's uniqueness is robust to the assumptions of either a logistic or a uniform (not shown) distribution of the stochastic migration cost.

23. The elasticity of substitution between skilled and unskilled workers may be smaller in developed than in developing countries, for which no comparable estimates exist.

24. Let the matching function be $M=a_{1} V^{\eta} N^{1-\eta}$, where $V$ is the number of vacancies and $N$ is the number of unemployed. Recall that $x=M / N$ is the worker's probability of finding a job. The probability of a firm of finding a worker can then be written as $M / V=a_{1}^{1 / \eta} x^{(\eta-1) / \eta}$. Therefore a firm that needs to hire $m$ workers must post $v=a_{1}^{-1 / \eta} x^{(1-\eta) / n} m$ vacancies. If we further assume that posting $v$ vacancies 
(for a survey, see Petrongolo and Pissarides 2001) and range from 0.1 to about 0.9, with most estimates lying somewhere between 0.3 and 0.5 . Shimer (2005) finds $\eta=0.27$ for the United States and Mortensen and Nagypal (2007) provide a point estimate of 0.54 for the same parameter. In addressing problems with both approaches, Brügemann (2008) reports $\alpha$ lying in the interval $[0.37,0.46]$. We thus consider values of $\eta$ equal to $0.27,0.46$, and 0.54 for our calibration exercise, which implies respective values for $\alpha$ of $2.7,1.17$, and 0.85 . Note that all the estimates for $\alpha$ (including the highest available estimate $\eta=0.54$, which corresponds to $\alpha=0.85$ ) satisfy the condition $\epsilon<(2+\xi+\alpha) /(1-\alpha \xi)$ for $\xi$ calibrated in what follows. For purposes of illustration we also include an unrealistically low value of $\alpha$ equal to 0.1 such that $\epsilon>(2+\xi+\alpha) /(1-\alpha \xi)$. In short, we consider the values $\alpha \in\{0.1,0.85,1.17,2.7\}$.

To calibrate the other parameters of the matching functions $a_{H}$ and $a_{L}$, we use equation (14) together with the equality $b_{j}=w_{j}$ and data on employment-weighted averages of wage rates and employment rates of the developing countries in our sample (i.e., for the set of non-OECD countries in our data). Because these parameters measure the efficiency of labor market institutions, our assuming them to be the same for all countries is a constraint imposed by data availability.

Consistently with the consensus in the international trade literature, we set the elasticity between varieties, $\sigma=4$. This is the mean value of the substitution elasticity estimates from Broda and Weinstein (2006), who use trade data to estimate this parameter. Similarly, Bernard et al. (2003) estimate a value of 3.8 when fitting US plant and macro data.

The technology frontier $A_{H}^{U S}, A_{L}^{U S}$ given by the level of technology in the United States is calibrated via the relations

$$
\begin{aligned}
& A_{H}^{U S}=\left(\frac{2 \sigma-1}{\sigma-1}\right)\left(w_{H}^{U S}\right)^{\frac{\epsilon}{\epsilon-1}}\left(\frac{H^{U S}}{Y^{U S}}\right)^{\frac{1}{\epsilon-1}}, \\
& A_{L}^{U S}=\left(\frac{2 \sigma-1}{\sigma-1}\right)\left(w_{L}^{U S}\right)^{\frac{\epsilon}{\epsilon-1}}\left(\frac{L^{U S}}{Y^{U S}}\right)^{\frac{1}{\epsilon-1}}
\end{aligned}
$$

These equalities can be derived, following the steps explained in Section 2.6, using information on skill endowments, wages, and income for the United States.

The parameter $\xi$, which measures the (inverse) cost of technology adoption, is calibrated using the relative employment rate of skilled workers (equation (27)) for the average developing country in our sample together with data for skill endowments and employment rates of the non-OECD countries in the sample. We find that the value of $\xi$ ranges between 0.05 and 0.4 , depending on $\epsilon$, and the values of $\xi$

costs $a_{2} v$ in terms of the final good, then a firm seeking to hire $m$ workers faces a hiring cost of $a x^{\alpha} m$ for $a=a_{2} / a_{1}^{1 / \eta}$ and $\alpha=(1-\eta) / \eta>0$. 
TABLE 1. Baseline choice of parameters.

\begin{tabular}{lccccccccc}
\hline Parameter & $w_{H}^{\mathrm{OECD}}$ & $w_{L}^{\mathrm{OECD}}$ & $x_{H}^{\mathrm{OECD}}$ & $x_{H}^{\mathrm{OECD}}$ & $a_{H}$ & $a_{L}$ & $\mu$ & $A_{H}^{U S}$ & $A_{L}^{U S}$ \\
\hline Value & 0.37 & 0.15 & 0.96 & 0.95 & 0.38 & 0.16 & 1.41 & 1.55 & 0.58 \\
\hline Parameter & $Z$ & $L$ & $\sigma$ & $c_{H}$ & $c_{L}$ & $\epsilon$ & $\alpha$ & $\xi$ & \\
\hline Value & 1.96 & 10 & 4 & 1.62 & 3.45 & 2.25 & 1.17 & 0.1 & \\
\hline
\end{tabular}

Note: The baseline parameters are taken from the literature or are calibrated to fit moments for the average developing country in our sample, as described in Section 3.1.

so obtained always satisfy the condition $2+\xi<\epsilon<(2+\xi+\alpha) /(1-\alpha \xi) .{ }^{25} \mathrm{We}$ choose a baseline value of $\xi$ equal to 0.1 such that, for $\alpha=0.1$, we also obtain a case where $\epsilon>(2+\xi+\alpha) /(1-\alpha \xi)$ for illustrative purposes.

To calibrate the cost parameter $\mu$ we use the equation for expected wages of skilled workers (36). We solve for $\mu$, while taking as given the employment-weighted averages of unskilled wages, employment rates, and migration rates of developing countries.

We also need parameter values for the OECD employment rates and wages. According to our data, the employment-weighted average of OECD employment rates is 0.96 for skilled and 0.95 for unskilled workers. Average yearly OECD wages (in terms of constant purchasing power parity) are around $\$ 37,000 \$ 15,000$ for skilled and unskilled workers, respectively. We therefore set $w_{H}^{\mathrm{OECD}}=0.37$ and $w_{L}^{\mathrm{OECD}}=0.15$ and set $x_{H}^{\mathrm{OECD}}=0.96$ and $x_{L}^{\mathrm{OECD}}=0.95$.

Finally, to obtain estimates of the average migration costs of skilled and unskilled workers, we calibrate $c_{H}$ and $c_{L}$ using the equations for the migration rates (35) to match exactly the migration rates of skilled and unskilled workers for the average developing country in our sample-given the average developing-country skill ratio $H / L=0.05$ and average working-age population of $L=10 .^{26}$ Table 1 summarizes the calibrated parameter values.

Our data consists of a sample of 62 developing countries for which we have information on skill endowments as well as on migration rates to the OECD, wages, and employment rates by skill attainment for the years 1990 and 2000. Throughout, we define skilled workers as those with at least some tertiary education and consider all other workers as unskilled. Data on emigration to the OECD by skill level are from Beine, Docquier, and Rapoport (2008); data on human capital come from Barro and Lee (2000, 2010) and De la Fuente and Domenech (2002). Data on wages by skill category are constructed using the data set collected by Freeman

25. Gancia, Müller, and Zilibotti (2011) estimate higher values for this parameter when fitting data on income to their model without unemployment; however, that model implies somewhat different structural relationships between factor endowments and endogenous variables than are implied by ours.

26. Given the presence of a negative scale effect (see equations (36) and (37)), we scale endowments so that the average employment rates take on realistic values. 
and Oostendorp (2000) while considering a fixed number of skilled and unskilled occupations. Unfortunately, we do not have wages by educational attainment, but we choose occupations so that they roughly correspond to our skill categories. Finally, unemployment rates by skill are constructed with information from the ILO Key Indicators of the Labour Market Database (2009). A more detailed discussion of the data set can be found in the Online Appendix along with a list of countries in the sample.

\subsection{Sensitivity Analysis}

Here, we conduct the experiment of increasing the endowment of skilled workers while holding constant the endowment of unskilled workers and study the resulting effect on employment, wages, and migration rates for a typical developing country in our sample. We analyze the effect on these outcomes of the elasticity of substitution and also of the matching elasticity.

3.2.1. The Effect of the Elasticity of Substitution. According to our model, the effects of changes in skill endowments on expected wages and emigration rates depend crucially on the elasticity of substitution between skilled and unskilled workers. Since employment rates are a positive monotonic transformation of wages, it follows that the pattern for expected wages is much like that for wages and employment rates separately. To save space we report results only for expected wages, but the reader should bear in mind that arguments concerning the skill ratio effects run analogously for wages and employment rates. Figure 8 (top) shows the expected wage of skilled relative to unskilled workers as a function of the skill ratio for different values of $\epsilon$ when $\alpha=1.17$ and $\xi=0.1$.

As predicted by the closed-economy model (Proposition 1), also with endogenous migration rates are the skill premium and the relative employment rate of skilled workers increasing in the skill ratio-provided $\epsilon \in(2+\xi,(2+\xi+\alpha) /(1-\alpha \xi))$ (i.e., for $\epsilon \in\{2.25,2.5\}$ ). In contrast, skill premia and relative employment rates are constant if $\epsilon=2.1(\epsilon=2+\xi)$ and are decreasing in the skill ratio for $\epsilon=1.75$ $(\epsilon<2+\xi)$. The positive relative wage and employment effects are greater for $\epsilon=2.5$ than for $\epsilon=2.25$ because the negative supply effect becomes weaker compared with the positive technology effect when $\epsilon$ is greater. Figure 8 (middle panel) shows how the change in expected relative wages translates into changes in the equilibrium relative emigration rates of skilled and unskilled workers; this is the brain drain. For $\epsilon=2.5$, the relative emigration rate of skilled workers is decreasing in the skill ratio. For $\epsilon=2.25$, the relative emigration rate of skilled workers decreases up to a skill ratio of around 0.3 and then starts to increase slightly. The intuition behind this relation between skill ratios and relative skilled migration rates can be gained by examining the absolute wage expressions (36) and (37). For $\epsilon \in(2+\xi,(2+\xi+\alpha) /(1-\alpha \xi))$, expected skilled wages for given migration rates are, on the one hand, increasing in the skill ratio because of the upward-sloping labor demand and, on the other hand, decreasing in absolute skill endowments because of the matching frictions 


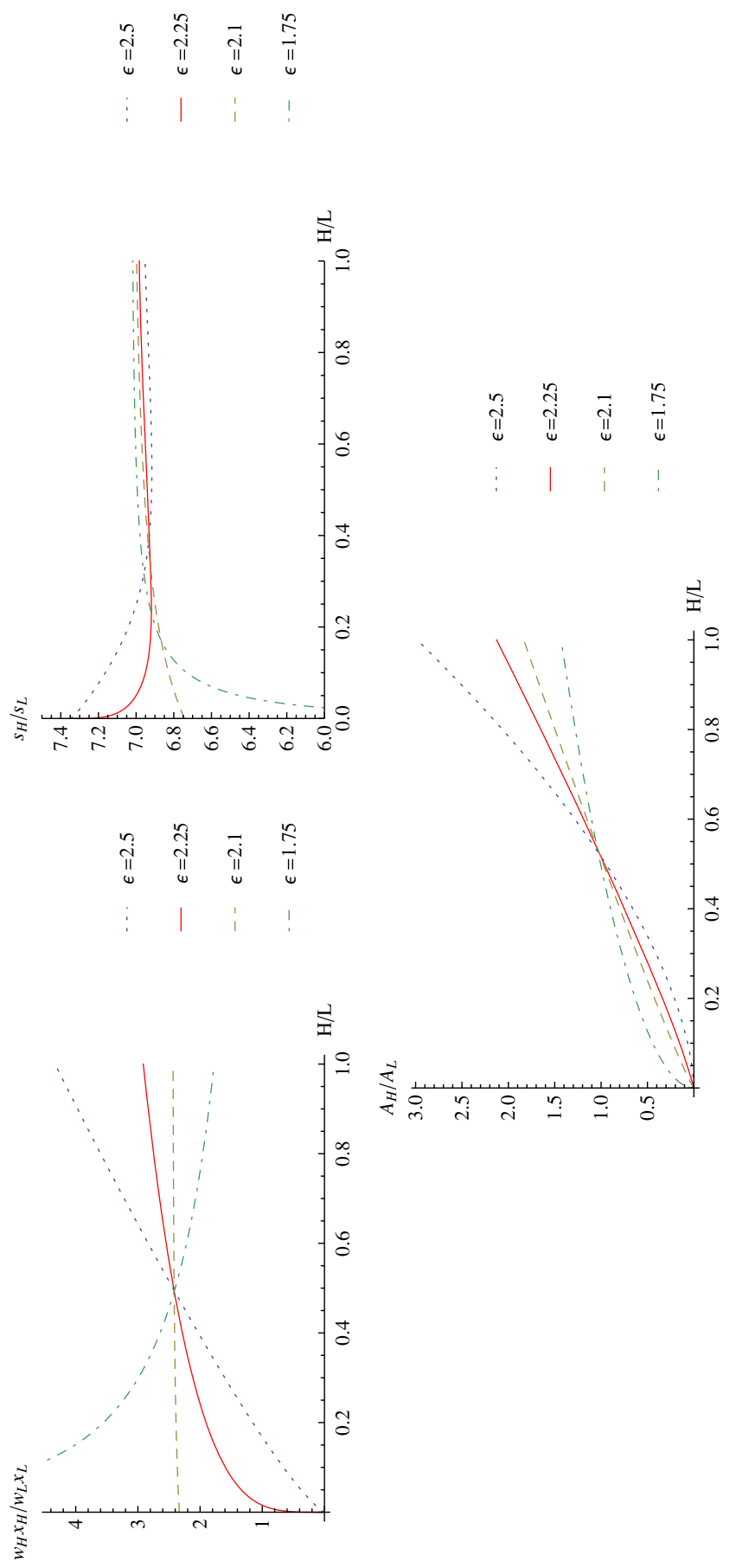

站

$\stackrel{2}{2} \stackrel{0}{=}$

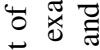

远

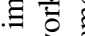

\& 3

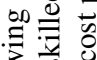

学芯言

हี 흥

疍

을

可

䨔焉

漹

.

(ㄷำ

$.00 \mathrm{~N}$

\%

坖

¿ 0

응

ป 컬

들 옥

ชิ

흘 তิ

ఏछ

ڤ્仓

च

总记芸

整萦方

ลิ

氖. 훙

㟧

范

융 눙

进

文히

: $\frac{\nabla}{\sim} \nabla$

䜦记

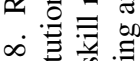

山.

品

ठ

पँ 
and the associated negative scale effect. The first (positive) first effect dominates for relatively low absolute values of skill endowments, whereas the second (negative) effect dominates for relatively high values. ${ }^{27}$ Hence, the relative emigration rate of skilled workers first decreases and then slightly increases, even though relative (but not absolute) expected skilled wages increase throughout. For $\epsilon=1.75$ the brain drain is increasing in the skill ratio: as relative expected wages of the skilled decrease, skilled workers' incentives to emigrate increase and their emigration rate increases relative to those of unskilled workers. For $\epsilon=2.1$, the skill premium does not change (since the technology and supply effects of a greater ratio of skilled employed exactly cancel each other), but the brain drain increases slightly because the difference in absolute expected wages between skilled and unskilled workers decreases.

Overall, the quantitative effects are most pronounced for low skill ratios (less than 0.2) and they become less important for greater skill ratios. We thus expect a greater impact of skill accumulation for relatively skill-scarce developing countries. The bottom panel of Figure 8 shows the effect of the skill ratio on the skill bias of technology for different values of the elasticity of substitution. Although the skill bias is positive for all values $\epsilon>1$, its increase is greater with greater $\epsilon$.

\subsubsection{The Effect of the Elasticity of the Wage Curve. Apart from the elasticity of} substitution between skilled and unskilled workers $\epsilon$ the sign and size of effects of the skill ratio on the labor market and emigration outcomes depends crucially on the elasticity of the wage curve $\alpha$. Figure 9 shows relative expected wages and emigration rates as well as the skill bias in technology for four different values of $\alpha \in\{0.1,0.85,1.17,2.7\}$ corresponding to the baseline specification (1.17) and other realistic values (and also an unrealistically small value). Because in this figure we keep $\epsilon$ constant at 2.25, the curves for $\alpha=1.17$ are exactly the same as those for $\epsilon=2.25$ in Figure 8. Again, if $\epsilon \in(2+\xi,(2+\xi+\alpha) /(1-\alpha \xi))$-for example, when $\alpha$ is equal to $0.85,1.17$, or 2.7 -then relative wages and employment rates of the skilled increase while the relative emigration rate of the skilled correspondingly decreases.

In contrast, if $\epsilon>(2+\xi+\alpha) /(1-\alpha \xi)$ (e.g., when $\alpha=0.1)$ then a greater skill ratio decreases relative expected skilled wages and increases the brain drain. The reason is that when labor market frictions are low enough for the elasticity of the wage curve to exceed the elasticity of labor demand firms cannot accommodate an increase in the supply of skilled workers. Instead, the relative number of skilled employees decreases, which decreases relative employment rates and wages of the skilled. In this case, the technological bias is clearly directed toward the unskilled (even though labor demand is upward-sloping, $\epsilon>2+\xi$ ) because a higher skill ratio corresponds to a lower ratio of skilled employees.

27. In turn, since endowments of unskilled workers are held constant, expected wages of the unskilled change only in response to the change in the skill ratio. This effect is unambiguously negative and so equilibrium unskilled emigration is unambiguously increasing in the skill ratio. 


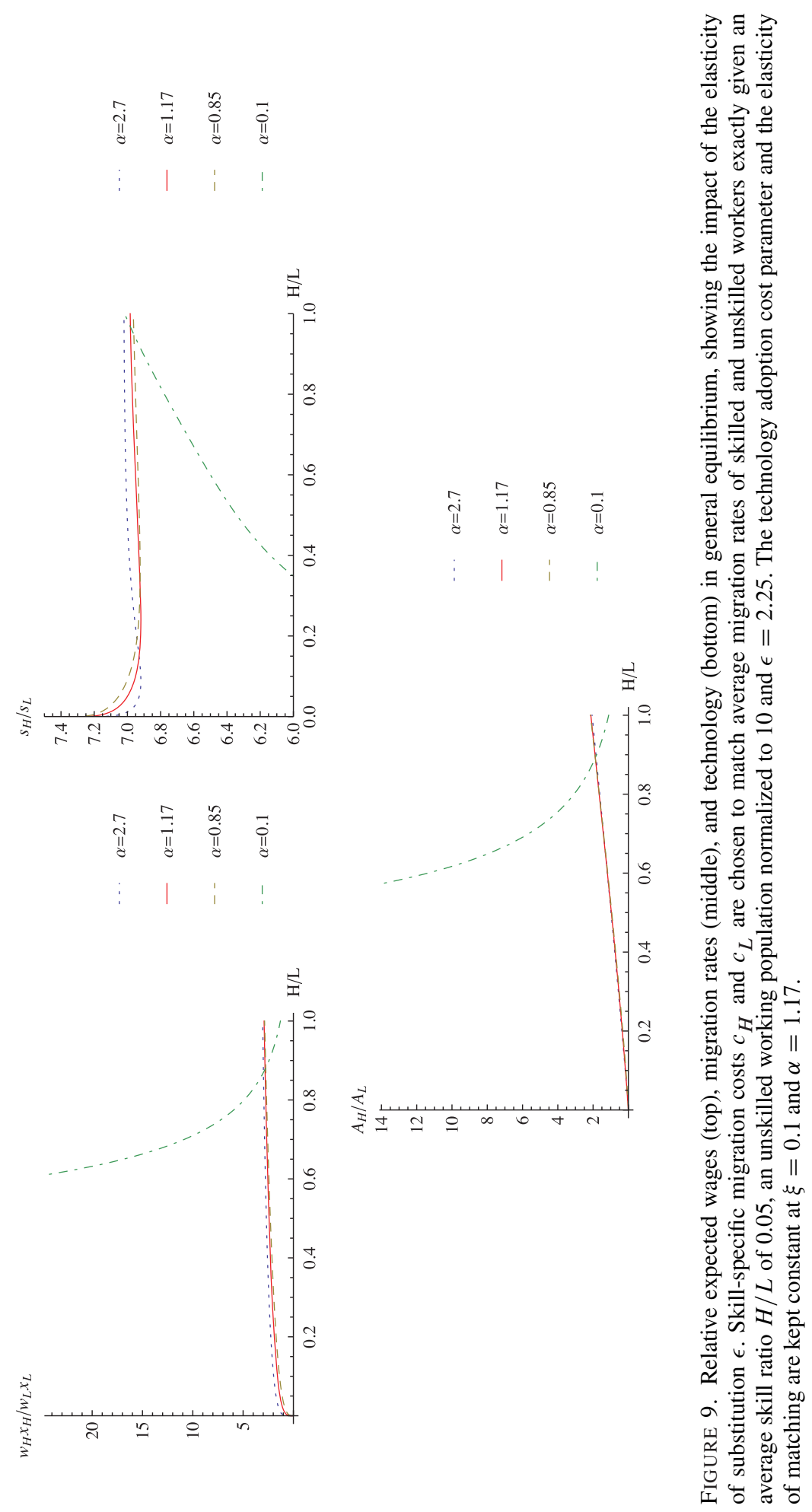




\subsection{Predicted and Actual Correlations}

In this section we compare the empirical relations between the skill ratio and the skill premium, relative productivity, unemployment, and the brain drain with the respective correlations predicted by our theoretical model in a quantitative simulation exercise. This approach allows us to determine how well our model performs in terms of predicting observed correlations between our variables of interest. We shall proceed as follows. First, in order to test the model, we calibrate all parameters using data from outside the model, as explained in Section 3.1. Second, we now use estimated migration costs for each country; ${ }^{28}$ Hence, we do not match any data moments by construction. Third, we simulate the model for the 62 non-OECD countries in our sample, ${ }^{29}$ viewing the OECD as a single destination and taking OECD wages and employment rates to be exogenous. We use data on skilled and unskilled workers for 1990 and 2000 and simulate the model for both years.

To assess model fit, we pool data for 1990 and 2000 and regress variables of interest on each other. We then compare the regression coefficients obtained with those obtained from running the same regressions on our simulated data. We compare coefficients from the following regressions (all in logs): (i) the regression of the relative unemployment rate of skilled workers on the skill ratio, (ii) the regression of the brain drain on the skill ratio, (iii) the regression of the skill premium on the skill ratio, (iv) the regression of the brain drain on the relative unemployment rate, (v) the regression of changes in the brain drain between 1990 and 2000 on changes in the skill ratio, and (vi) the regression of relative productivity of skilled workers on the skill ratio. ${ }^{30}$ Our baseline calibration is again $\epsilon=2.25$ and $\alpha=1.17$, but we also report results for $\epsilon \in\{2.1,2.5\}$ and $\alpha \in\{0.85,2.7\}$.

The results of this exercise are presented in Table 2. The first row gives the regression coefficients obtained from the data; subsequent rows report regression coefficients computed with the simulated data for different parameter values. Turning first to our baseline calibration with $\epsilon=2.25$ and $\alpha=1.17$ (boldface type in row 6), the model is able to replicate the signs of virtually all coefficients as well as the approximate magnitudes of some. Despite our parsimonious calibration, the model fits

28. We regress the logistic transformation of migration rates on the skill ratio and migration cost controls while instrumenting for the skill ratio with public education expenditure,

$$
\log \left(s_{j} /\left(1-s_{j}\right)\right)_{i t}=\alpha+\beta \log (H / L)_{i t}+\gamma \log (c)_{i j}+\mu_{t}+v_{i t},
$$

Then the predicted migration costs are given by

$$
\hat{c}_{i H}=-0.25^{(*)} \log (\text { distance })-0.08 \text { Colony }+1.01^{(* *)} \text { English }-0.11 \text { French }\left(R^{2}=0.31\right)
$$

and

$$
\hat{c}_{i L}=-0.66^{(* *)} \log (\text { distance })-0.54 \text { Colony }+0.72^{(* * *)} \text { English }-0.18 \text { French }\left(R^{2}=0.33\right) .
$$

29. Including OECD countries in the simulations has little effect on the results (available on request).

30. Data on $A_{H} / A_{L}$ are constructed using equation (18). 


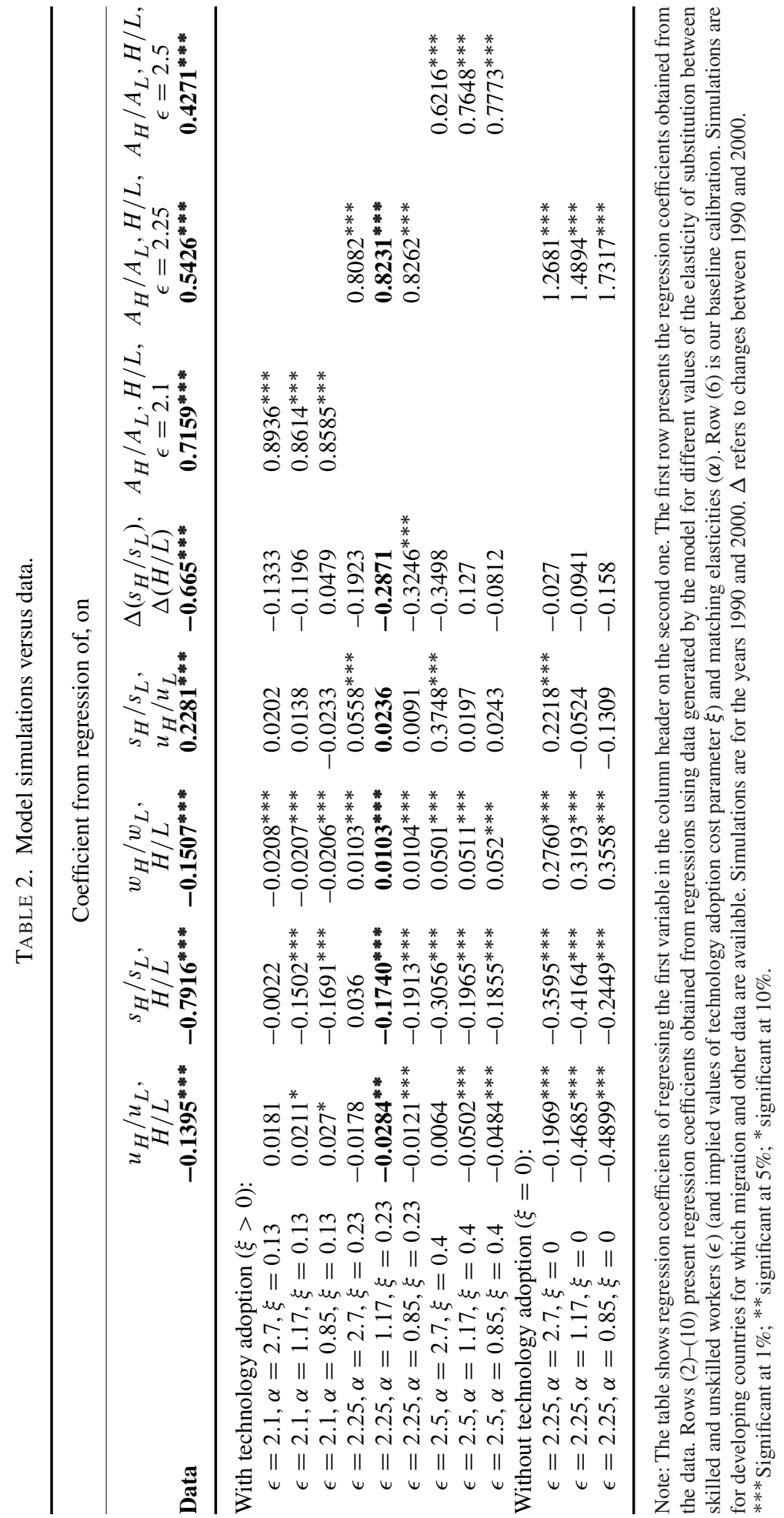


the sign for the coefficient of the regression of relative unemployment rates on skill ratios $(-0.03$, compared with -0.14 in the data), that of brain drain and skill ratios $(-0.17$ versus -0.79 in the data), that between brain drain and relative unemployment rates ( 0.02 versus 0.23 in the data), between changes in the brain drain and changes in the skill ratio $(-0.29$ versus -0.67 in the data) and between relative productivities and the skill ratio ( 0.82 versus 0.54 in the data). The only coefficient that our model does not replicate well is the one for the regression of the skill premium on skill ratios ( 0.01 compared with -0.15 in the data). This is not surprising, however, when one considers that our model with labor market frictions always predicts the same sign for the relation between wages and the skill ratio as for that between employment rates and the skill ratio.

We now briefly discuss results for different values of $\epsilon$ and $\alpha$. For $\epsilon=1.75$ the calibrated value for $\xi$ turns negative, which is outside the permissible range; hence we do not report these results. For $\epsilon=2.1$, the regression coefficients are in general too small and often insignificant. For $\epsilon=2.5$, the signs of the coefficients are the same as for $\epsilon=2.25$ and the magnitudes of the coefficients are also similar. Turning now to changes in $\alpha$ for $\epsilon=2.25$, we observe that our results are not sensitive to the value of this parameter (if the condition $\epsilon>2+\xi$ is satisfied). For both high and low values of $\alpha$, the signs of the regression coefficients are mostly maintained, but the magnitudes generally correspond less well to the data.

In the rows at the bottom of Table 2 we present results for the model without technology adoption $(\xi=0)$, where each country develops its technology individually. For this model, the magnitudes of the simulated coefficients are closer to those of the data than were those for the model with technology adoption (given $\epsilon>2$ ). Consider in particular the case $\epsilon=2.25$ and $\alpha=0.85$. With this calibration, the coefficient of the regression of relative unemployment rates on skill ratios becomes -0.20 (compared to -0.14 in the data), that of brain drain and skill ratios equals -0.36 (compared with -0.79 in the data), that between brain drain and relative unemployment rates is 0.22 (versus 0.23 in the data), that between changes in the brain drain and changes in the skill ratio is -0.03 (versus -0.67 in the data) and that between relative productivities and the skill ratio is 1.27 (compared with 0.54 in the data). These results indicate that our model requires rather large technology adoption costs to get the correlations right in terms of magnitude-which is not particularly surprising, since our mechanism relies on technology and expected wages reacting strongly in response to changes in skill endowments.

We thus conclude that a simple model of migration-one with endogenously directed technology and in which $2+\xi<\epsilon<(2+\xi+\alpha) /(1-\alpha \xi)$-performs reasonably well in terms of replicating the correlations, observed in the data, between skill ratios and skill-specific labor market outcomes and migration rates. Yet, the same model with $\epsilon<2+\xi$, which implies a downward-sloping relative demand curve for skilled labor, cannot replicate the salient features of the data. We take this finding as support for the mechanisms emphasized in our model. 


\section{Conclusion}

In this paper we present a model of directed technology adoption, frictional unemployment, and migration to examine the effects of a change in skill endowments on wages, employment rates, and emigration rates of skilled and unskilled workers. We find that, for plausible parameter values - of the elasticity of substitution between skilled and unskilled workers, the elasticity of matching workers to jobs, and technology barriers-returns to skill are an increasing function of skill ratios in the presence of endogenous skill-biased technology: an increase in the relative stock of skilled workers leads to lower relative unemployment rates and higher skill premia. Hence, the relative expected wage rate of skilled workers increases, resulting in a lower relative emigration rate of skilled workers (brain drain).

We provide simulations of wages, employment rates, and emigration rates to confirm that increases in the skill ratio have potentially sizable effects on these outcomes. Moreover, we show that such labor market institutions as unemployment benefits and firing costs interact with skill ratios to determine the direction of technological change. An increase in the skill ratio triggers skill-biased technological change if unemployment benefits and firing costs are sufficiently low, but if these values are high then the result may be technological change that is not skill biased. Our findings also fit the stylized facts on improved education in developing countries during the 1980s and the consequent decrease in the brain drain during the 1990s. These results suggest that education policies can significantly reduce the brain drain and thereby improve long-run prospects for growth and prosperity in the countries from which skilled workers would otherwise emigrate.

\section{Appendix}

The expressions for employment rates and wages used to derive equations (36) and (37) are

$$
\begin{aligned}
& x_{H}=\left[{\frac{\mu a_{H}^{\xi}(2 \sigma-1)^{1+\xi}}{Z\left(1-s_{H}\right) H(\sigma-1)^{\xi} A_{H}^{U S \xi}}}^{\frac{1}{1-\alpha \xi}}(1+A)^{-\frac{(1+\xi)}{(\epsilon-1)(1-\alpha \xi)}}\right]^{1+\alpha}, \\
& x_{L}=\left[{\frac{\mu a_{L}^{\xi}(2 \sigma-1)^{1+\xi}}{\left(1-s_{L}\right) L(\sigma-1)^{\xi} A_{L}^{U S \xi}}}^{\frac{1}{1-\alpha \xi}}\left(1+A^{-1}\right)^{-\frac{(1+\xi)}{(\epsilon-1)(1-\alpha \xi)}}\right]^{1+\alpha},
\end{aligned}
$$

where

$$
\begin{aligned}
& A \equiv Z^{\frac{(1+\alpha)(1+\xi)(1-\epsilon)}{\alpha(1+\epsilon \xi)-(\epsilon-2-\xi)}}\left(\frac{a_{L}}{a_{H}}\left(\frac{\left(1-s_{H}\right) H}{\left(1-s_{L}\right) L}\right)^{\alpha}\right)^{-\frac{(\epsilon-1)(1+\xi)}{\alpha(1+\epsilon \xi)-(\epsilon-2-\xi)}}\left(\frac{A_{H}^{U S}}{A_{L}^{U S}}\right)^{-\frac{\xi(\epsilon-1)(1+\alpha)}{\alpha(1+\epsilon \xi)-(\epsilon-2-\xi)}}, \\
& w_{H}=a_{H} x_{H}^{\alpha}, \text { and } w_{L}=a_{L} x_{L}^{\alpha} .
\end{aligned}
$$




\section{References}

Acemoglu, Daron (1998). "Why Do New Technologies Complement Skills? Directed Technical Change and Wage Inequality." Quarterly Journal of Economics, 113, 1055-1089.

Acemoglu, Daron (2002). "Directed Technical Change." Review of Economic Studies, 69, 781-809.

Acemoglu, Daron (2003). "Patterns of Skill Premia." Review of Economic Studies, 70, 199-230.

Acemoglu, Daron and Fabrizio Zilibotti (2001). "Productivity Differences" Quarterly Journal of Economics, 116, 563-606.

Acemoglu, Daron, Philippe Aghion and Fabrizio Zilibotti (2006). "Distance to Frontier, Selection and Economic Growth." Journal of the European Economic Association, 4, 37-74.

Barro, Robert and Jong-Wha Lee (2000). "International Data on Educational Attainment: Updates and Implications." CID Working Paper No. 42.

Barro, Robert and Jong-Wha Lee (2010). "Educational Attainment in the World, 1950-2010.” NBER Working Paper No. 15902.

Beine, Michel, Frederic Docquier and Hillel Rapoport (2001). "Brain Drain and Economic Growth: Theory and Evidence." Journal of Development Economics, 64, 275-289.

Beine, Michel, Frederic Docquier and Hillel Rapoport (2008). "Brain Drain and Human Capital Formation in Developing Countries: Winners and Losers." Economic Journal, 118, 631-652.

Bernard, Andrew, Jonathan Eaton, Bradford Jensen and Samuel Kortum (2003). "Plants and Productivity in International Trade." American Economic Review, 93(4), 1268-1290.

Blanchard, Olivier and Jordi Gali (2010). "Labor Markets and Monetary Policy: A New-Keynesian Model with Unemployment.” American Economic Journal: Macroeconomics, 2, 1-30.

Broda, Christian and David Weinstein (2006). "Globalization and the Gains from Variety." Quarterly Journal of Economics, 121, 541-585.

Brügemann, Bjoern (2008). "What Elasticity of the Matching Function is Consistent with U.S. Aggregate Labor Market Data?" Working paper, Yale University.

Caselli, Francesco and Wilbur John Coleman II (2006). “The World Technology Frontier.” American Economic Review, 96(3), 499-522.

Chor, Davin (2001). "Skilled and Unskilled Wages in a Globalizing World, 1968-1998." Working paper, Singapore Management University, School of Economics.

Ciccone, Antonio and Giovanni Peri (2006). "Identifying Human-Capital Externalities: Theory with Applications." Review of Economic Studies, 73, 381-412.

Coe, David, Elhanan Helpman and Alexander Hoffmaister (2009). "International R\&D Spillovers and Institutions." European Economic Review, 53, 723-741.

De la Croix, David and Frederic Docquier (2012). "Do Brain Drain and Poverty Result from Coordination Failures?" Journal of Economic Growth, 17, 1-26

De la Fuente, Angel and Rafael Domenech (2002). "Human Capital in Growth Regressions: How Much Difference Does Data Quality Make? An Update and Further Results." CEPR Discussion Paper No. 3587.

Diamond, Peter (1981). "Mobility Costs, Frictional Unemployment and Efficiency." Journal of Political Economy, 89, 798-812.

Epifani, Paolo and Gino Gancia (2008). "The Skill Bias of World Trade." Economic Journal, 118, 927-960.

Fadinger, Harald and Karin Mayr (2011). "Skill-Biased Technological Change, Unemployment and Brain Drain.” University of Vienna, Department of Economics Working Paper No. 1108.

Freeman, Richard and Remco Oostendorp (2000). "Wages Around the World: Pay Across Occupations and Countries." NBER Working Paper No. 8058.

Gancia, Gino and Fabrizio Zilibotti (2009). "Technological Change and the Wealth of Nations." Annual Review of Economics, 1, 93-120.

Gancia, Gino, Andreas Müller and Fabrizio Zilibotti (2011). "Structural Development Accounting." CEPR Discussion Paper No. 8254.

Grogger, Jeffrey and Gordon Hanson (2011). "Income Maximization and the Selection and Sorting of International Migrants." Journal of Development Economics, 95, 42-57. 
Grossmann, Volker and David Stadelmann (2011). "Does International Mobility of High-Skilled Workers Aggravate Between-Country Inequality?" Journal of Development Economics, 95, 8894.

Helpman, Elhanan and Oleg Itskhoki (2007). "Labor Market Rigidities, Trade and Unemployment." NBER Working Paper No. 13365.

Helpman, Elhanan and Oleg Itskhoki (2010). "Labor Market Rigidities, Trade and Unemployment." Review of Economics Studies, 77, 1100-1137.

International Labour Organization (2009). Key Indicators of the Labor Market, 6th ed. ILO.

Mortensen, Dale (1970). "A Theory of Wage and Employment Dynamics." In Microeconomic Foundations of Employment and Inflation Theory, edited by E. S. Phelps et al. Macmillan.

Mortensen, Dale and Eva Nagypal (2007). "More on Unemployment and Vacancy Fluctuations." Review of Economic Dynamics, 10, 327-347.

Mountford, Andrew (1997). "Can a Brain Drain be Good for Growth in the Source Economy?" Journal of Development Economics, 53, 287-303.

Nelson, Charles and Edmund Phelps (1966). "Investment in Humans, Technological Diffusion, and Economic Growth." American Economic Review, 56(2), 67-75.

Petrongolo, Barbara and Christopher Pissarides (2001). "A Survey of the Matching Function." Journal of Economic Literature, 39, 390-431.

Pissarides, Christopher (2000). Equilibrium Unemployment Theory, 2nd ed. Basil Blackwell/MIT Press.

Shimer, Robert (2005). "The Cyclical Behavior of Equilibrium Unemployment and Vacancies." American Economic Review, 95(1), 25-49.

Stark, Odett, Christian Helmenstein and Alexia Prskawetz (1997). “A Brain Gain with a Brain Drain.” Economics Letters, 55, 227-234.

Stark, Odett, Christian Helmenstein and Alexia Prskawetz (1998). "Human Capital Depletion, Human Capital Formation and Migration: A Blessing or a 'Curse'?" Economics Letters, 60, 363-367.

Stole, Lars and Jeffrey Zwiebel (1996a). "Intra-Firm Bargaining under Non-binding Contracts." Review of Economic Studies, 63, 375-410.

Stole, Lars and Jeffrey Zwiebel (1996b). "Organizational Design and Technology Choice under Intra-firm Bargaining.” American Economic Review, 86(1), 195-222.

Thoenig, Mathias and Thierry Verdier (2003). "A Theory of Defensive Skill-Biased Innovation and Globalization.” American Economic Review, 93(3), 709-728.

\section{Supporting Information}

Additional Supporting Information may be found in the online version of this article at the publisher's website:

Online Appendix A.1. Data. 